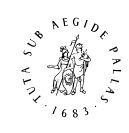

B R I L L

\title{
Temperature-Based Crossmodal Correspondences: Causes and Consequences
}

\author{
Charles Spence* \\ Crossmodal Research Laboratory, Oxford University, Oxford, UK \\ Received 28 June 2019; accepted 13 November 2019
}

\begin{abstract}
The last few years have seen an explosive growth of research interest in the crossmodal correspondences, the sometimes surprising associations that people experience between stimuli, attributes, or perceptual dimensions, such as between auditory pitch and visual size, or elevation. To date, the majority of this research has tended to focus on audiovisual correspondences. However, a variety of crossmodal correspondences have also been demonstrated with tactile stimuli, involving everything from felt shape to texture, and from weight through to temperature. In this review, I take a closer look at temperature-based correspondences. The empirical research not only supports the existence of robust crossmodal correspondences between temperature and colour (as captured by everyday phrases such as 'red hot') but also between temperature and auditory pitch. Importantly, such correspondences have (on occasion) been shown to influence everything from our thermal comfort in coloured environments through to our response to the thermal and chemical warmth associated with stimulation of the chemical senses, as when eating, drinking, and sniffing olfactory stimuli. Temperature-based correspondences are considered in terms of the four main classes of correspondence that have been identified to date, namely statistical, structural, semantic, and affective. The hope is that gaining a better understanding of temperature-based crossmodal correspondences may one day also potentially help in the design of more intuitive sensory-substitution devices, and support the delivery of immersive virtual and augmented reality experiences.
\end{abstract}

\section{Keywords}

Crossmodal correspondences, temperature, thermal, colour, pitch, intensity, emotional mediation, chemical senses

\section{Introduction}

There has been a rapid growth of interest in the topic of crossmodal correspondences in recent years. Crossmodal correspondences are the sometimes

\footnotetext{
${ }^{*}$ E-mail: charles.spence@psy.ox.ac.uk
} 
surprising associations that people experience between stimuli, attributes, or perceptual dimensions, such as, for example, between auditory pitch and visual size (e.g., Evans and Treisman, 2010; Gallace and Spence, 2006), or elevation (e.g., Parise et al., 2014; see Deroy et al., 2018, for a review). To date, the majority of the research in this area has tended to focus on crossmodal correspondences between auditory and visual stimuli (Evans and Treisman, 2010; Parise and Spence, 2012; see Marks, 2004; Spence, 2011, 2018a, for reviews). However, a rich variety of robust crossmodal correspondences have now been demonstrated between various other pairs of sensory modalities (e.g., Parise, 2016), such as, for example, between colours and tastes (e.g., Saluja and Stevenson, 2018; see Spence, 2019a; Spence et al., 2015, for reviews) and olfactory stimuli (e.g., Demattè et al., 2006; Gilbert et al., 1996; Kim, 2013; Levitan et al., 2014; Schifferstein and Tanudjaja, 2004; Stevenson et al., 2012).

Of particular interest with respect to the themes of the present review are those crossmodal correspondences involving dimensions of tactile/haptic experience (see Asad et al., 2016; Eitan and Rothschild, 2011; Jraissati and Wright, 2018; Sourav et al., 2019). To date, a number of tactile crossmodal correspondences have been reported involving everything from felt shape/size (e.g., Walker and Smith, 1984, 1985, 1986) to texture and hardness (Ludwig and Simner, 2013; Slobodenyuk et al., 2015) (see Note 1), and from weight (Walker et al., 2017) through to temperature (e.g., Wang and Spence, 2017). There has also been a recent resurgence of interest in what Marinetti, the Italian Futurist, once called 'syn-tactilismo' (Marinetti, 1932/2014; see also Marinetti, 1921, on 'Tattilismo'). Indeed, the latest research has demonstrated a crossmodal influence of felt texture on various aspects of taste/flavour/mouthfeel (e.g., see Biggs et al., 2016; Carvalho et al., in press; Slocombe et al., 2016; Van Rompay and Groothedde, 2019; Wang and Spence, 2018). That said, at least for those correspondences involving tactile size/shape, texture (Kanaya et al., 2016), and elevation (Occelli et al., 2009), dimensions that can be readily experienced visually, it is sometimes unclear whether such correspondences might not be mediated by visual representations (see Biggs et al., 2016; Deroy et al., 2016; Hamilton-Fletcher et al., 2018; Sourav et al., 2019). In this review, though, I specifically want to take a closer look at temperature-based, or thermal, correspondences.

\section{Accounting for Touch-Based Crossmodal Correspondences}

Over the years, a number of explanations for the existence of crossmodal correspondences have been put forward. According to Spence (2011, 2018a), the most likely cause for many crossmodal correspondences is the internalization of the natural statistics of the environment, perhaps as coupling priors 
according to Bayesian Decision Theory (see Ernst, 2007; Parise et al., 2014). However, it is also possible that a few correspondences may have a structural origin, based on the common neural encoding of stimulus dimensions such as, for example, intensity. This account, first put forward by Stevens (1957), might be expected to offer an explanation for intensity-based correspondences, such as presumably the pairing of loud sounds and bright lights with high temperatures (e.g., Bond and Stevens, 1969; Marks, 1974, 1987, 1989; Marks, Szczesiul and Ohlott, 1986; Stevens and Marks, 1965) (Note 2). According to a third, semantic (or, perhaps better said, linguistic), account, the use of the same adjectives to describe different aspects of our sensory experience might also underpin, or at the very least serve to strengthen, certain crossmodal correspondences (see Martino and Marks, 1999, 2000, 2001, on the 'semantic coding hypothesis'). Think here only of how people often talk of 'warm' and 'cool' colours such as red and blue (or colour temperature), not to mention using terms such as 'red hot' (Divard and Urien, 2001; Hardin, 2000; Kimura, 1950; Ross, 1938; von Allesch, 1925; Wastiels et al., 2012) (Note 3). Finally, according to the emotional mediation account, people may match particular stimuli because they share, or evoke the same emotional, or affective associations (e.g., Palmer et al., 2013; Schifferstein and Tanudjaja, 2004; Velasco et al., 2015; Wright et al., 2017; see also Elliott, 2019; Jonauskaite et al., 2019; Woods et al., 2013). However, given the fact that the common use of linguistic terms may itself simply be picking up on statistical links, or correlations, that are present in the environment (see Martino and Marks, 1999, p. 904), these various accounts should not be considered as mutually exclusive (see Spence, 2011, 2018a) (Note 4).

In fact, all four of these accounts may have some explanatory validity (or at least plausibility) in terms of accounting for temperature-based crossmodal correspondences. In terms of the statistical account, there are, after all, likely to be a number of natural relationships between ambient colour and temperature (e.g., Collins, 1965; see also Ho et al., 2014a) as well as between temperature and sound qualities (Velasco, Jones, King, and Spence, 2013a, b; Wang and Spence, 2017) (Note 5). So, for instance, colour lightness is one consequence of heating (MacIsaac et al., 1999). Note also how red-hot/warm and blue-cold is used as the code on taps/faucets around the world (though see Tomaselli, 2001). It is, though, important to highlight the fact that it is often difficult to assess the veracity of these ecological accounts positing statistical regularities in the environment that observers might, or might not, pick up on, and thereafter internalize, perhaps in terms of coupling priors (see Ernst, 2007; Slobodenyuk et al., 2015).

The hedonic, affective, or emotional account can presumably also explain some of the crossmodal correspondences involving tactile stimuli, at least 
given recent research showing that people tend to consistently associate different emotions with different felt textures (e.g., see Essick et al., 2010; Etzi et al., 2014, 2016; Iosifyan and Korolkova, 2019; Iosifyan et al., 2017; see also Cabanac, 1979; Hertenstein et al., 2006, 2009; Picard et al., 2003). It certainly feels natural to want to associate temperatures with emotions / affective responses (Williams and Bargh, 2008; though see also Chabris et al., 2019, for two failures to replicate the results of the latter study). So, having provided a quick summary of the four main potential explanations for any temperaturebased correspondences, I now want to take a closer look at the evidence in this area, reviewing the research suggesting the existence of a correspondence between thermal cues and both visual and auditory stimuli. Thereafter, I critically evaluate the empirical evidence suggesting that such temperature-based crossmodal correspondences may sometimes lead to colour biasing/modifying our perception of temperature / thermal comfort (Pöllmann, 1994).

\section{Temperature-Based Correspondences: Their Existence and Consequences}

Temperature is a cue, or source of information, that is closely (primarily) tied to the somatosensory system (e.g., Gallace and Spence, 2014; McGlone and Spence, 2010; Nafe, 1934). At the same time, however, a number of crossmodal correspondences involving this dimension have been documented in the literature with both visual (colour) and also sonic stimuli (especially pitch). One of the reasons as to why temperature-based correspondences are so interesting relates to the fact that feelings of warming/cooling can be elicited both thermally (e.g., by radiant heat) and chemaesthetically (e.g., through skin contact with capsaicin/menthol, etc.; Green, 1992a). Of course, warm and cold feelings can also be elicited internally (e.g., as when we feel a chill, or feel overheated following strenuous exercise, as a result of vasodilation/vasoconstriction) (Note 6). Indeed, we are aware both of the temperature of our own body (based, presumably, on interoceptive cues/signals; see Craig, 2002, for a review), as well as being aware of the temperature of the environment in which we happen to find ourselves (cf. Stevens and Hooper, 1982). It is, I think, a priori unclear which, if any, of these sources of information about temperature actually underpin the colour-temperature correspondences that have been observed to date.

When considering temperature-colour correspondences, there are at least two, putatively independent, questions that can be asked. The first concerns the very existence of a crossmodal correspondence between colour and temperature, and, if such a correspondence should happen to be demonstrated, what precisely the nature of the mapping might be (i.e., is the colour red associated with warm or cold?). It is undoubtedly a widely-held belief that certain 
colours impart warmth, while others convey a notion of coolness (e.g., Arnheim, 1954; Itten, 2002; Ross, 1938). And, having demonstrated the existence of a robust colour-temperature correspondence, the other question that one can ask concerns whether people's perception of temperature (or thermal comfort) may be modified by exposure to colour cues (such as coloured lights or surfaces, i.e., luminous and non-luminous, or reflective, colours, respectively). Those studies that have addressed the latter question have typically assessed people's perception of the temperature of a variety of stimuli, including surfaces (i.e., colour patches or abstract colour chips; Osgood et al., 1957; Taft, 1997), objects (Note 7), and environments, as well as the thermal comfort of the observers themselves.

It is worth stressing that, at least until recently, the evidence in support of the latter claim that colour cues might influence temperature perception was weak and seemingly inconsistent. Indeed, some commentators have been minded to conclude that the empirical research shows little more than a purely intellectual or cognitive association. For example, Mogensen and English (1926, p. 427) talk of 'apparent' or 'psychological' warmth. Berry (1961, p. 250), meanwhile, describes his participants persisting: "in the conventional belief that green and blue are "cool" colors when asked to rank the colors that they had experienced". This belief, though, does not carry over to hues and colours impacting on our actual sensations of thermal heat or comfort in any meaningful sense (Note 8). Or, take Winzen et al.'s (2014, p. 466) claim that"colour has a certain perceived thermal virtue".

On the other hand, the significant effects on perceived/rated temperature reported in certain studies appear to demonstrate a contrast effect between seen colour and felt temperature, rather than an assimilation effect, as one might intuitively have expected. Another issue that the researchers working in this area have been rather unclear about is whether such temperature-colour correspondences, or associations, "are innate or if they are acquired through experience" (Fenko et al., 2010, p. 1326). Relevant here, the innate account, at least as best one can understand it, would appear to predict an influence of colour (specifically luminous colour) on temperature but little influence of temperature on colour perception. By contrast, the literature has thus far cast crossmodal correspondences as bidirectional phenomena, meaning that the correspondence between colour and temperature should be just as robust as the association going in the opposite direction (and, importantly, regardless of whether the colour is luminous or not, i.e., reflective) (Note 9). This is just one of the differences between crossmodal correspondences and synaesthesia with which they have often been confused (see Martino and Marks, 2001; Walker and Smith, 1985; and Deroy and Spence, 2013, for arguments against conflating these two phenomena). Notice here also that crossmodal correspondences have not only been documented between pairs of sensory stimuli/dimensions but also 
between words referring to those sensations (see O'Mahony, 1983; Spence et al., 2015; Wright et al., 2017).

There are two other issues to bear in mind when considering the somewhat inconsistent and confusing evidence regarding colour-temperature correspondences that follows (see Table 1 for a partial summary). The first concerns the unity effect. While the colour and temperature cues used in certain studies belong to the same stimulus, object, or event, in others they belong to separate stimuli/objects/events. Given the importance of the unity effect to multisensory integration (see Chen and Spence, 2017, for a review), one might have expected that this factor would have played an important role in determining the kinds of crossmodal interactions that are observed, if not the nature of the crossmodal mappings that people make. To be clear, when the observer has reason to believe that the colour and temperature stimuli belong to the same object or event then the likelihood of crossmodal influence, or multisensory integration, is presumably increased. However, the strength and robustness of crossmodal correspondences experienced as a phenomenal match between stimuli appears to be unaffected by whether the comparison stimuli belong to the same object/event or not. One might also wonder whether the difference between the studies reporting assimilation $v s$ contrast can be tied to the sensory inputs belonging to the same $v s$ different objects.

The second point to bear in mind here concerns whether the colour is reflective or illuminant/luminous (e.g., Shen et al., 1999; Yasukouchi et al., 2000). This factor, which once again has varied between studies (see Table 1), has, on occasion, been shown to make a difference to the kinds of crossmodal correspondences with visual stimuli that have been observed. For example, Marks (1987) documented a crossmodal correspondence between both lightness and brightness and auditory pitch, while at the same time reporting that brightness (but not lightness) corresponded with auditory loudness.

\subsection{Early Studies of Colour-Temperature Correspondences}

In one of the first studies to have been conducted on colour-temperature correspondences, Mogensen and English (1926) had their participants $(n=25)$ judge which of two, equally warm, cylinders felt warmer. The cylinders (actually slide rheostats) were kept at a constant temperature of $42^{\circ} \mathrm{C}$. The participants placed their hands on grey surfaces held at $36^{\circ} \mathrm{C}$ between trials. The cylinders had been wrapped in papers of different saturated colours (green, blue, yellow, orange, purple, and red). In total, the participants were presented with a cylinder of each colour on 30 trials each. This meant that scores ranged from 0 (if none of the participants ever thought that the cylinder of a particular colour was warmer) through to a maximum total score of 750 (i.e., 25 participants $\times 30$ trials) if every participant always responded that a particular colour felt warmer. 
C. Spence / Multisensory Research 33 (2020) 645-682

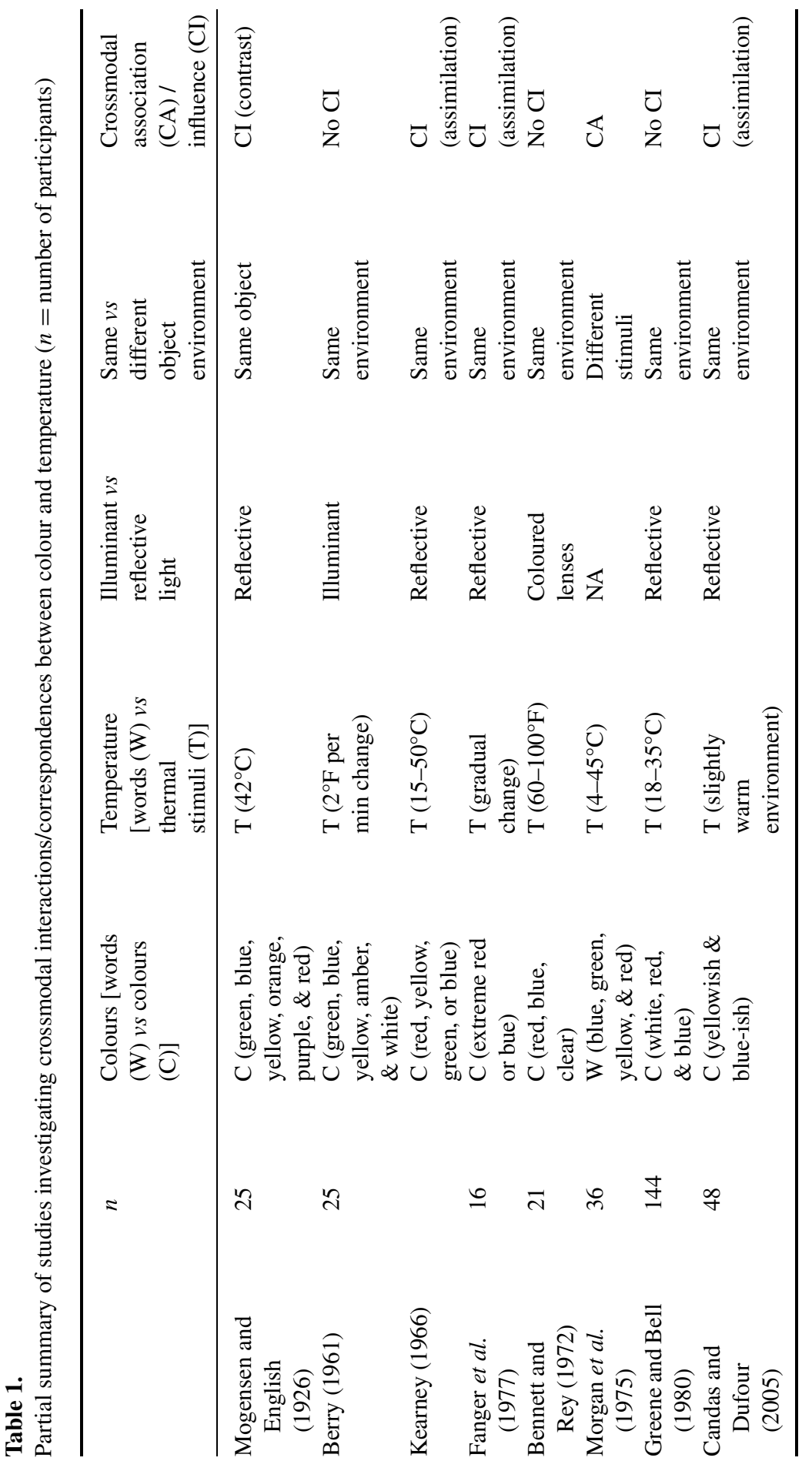




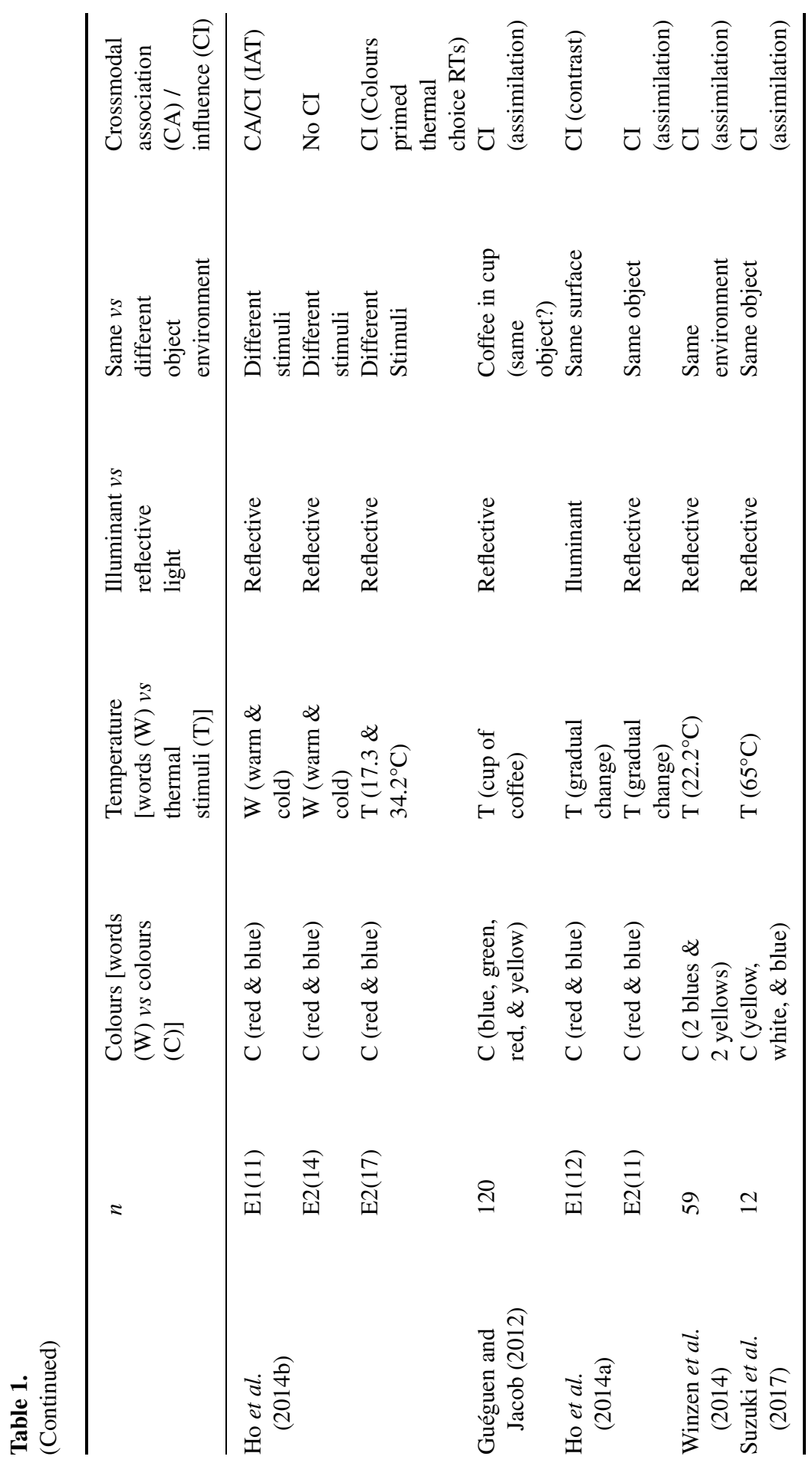


The results of this early study revealed numerical differences between the differently-coloured cylinders, though the pattern of results was somewhat hard to explain, at least for the researchers themselves. If anything, the results appeared more consistent with a contrast, rather than an assimilation, account. In particular, the cylinder covered in 'royal purple' paper was rated as the warmer of the two cylinders less frequently than any of the other colours: purple - 301; red - 371; yellow - 377; orange - 380; blue - 405; green 416. It is, though, worth noting that no formal statistical tests were conducted. The closest we get is the following statement from Mogensen and English (1926, p. 428): "The superior 'warmth' value ascribed to green and blue as compared to purple can scarcely be attributed to chance" (Note 10).

In a paper published in 1961, Berry exposed 25 participants to five colours of light (green, blue, yellow, amber, and white) in a counterbalanced order. In each test, the ambient temperature in the test room was increased slowly (by $2^{\circ} \mathrm{F}$ per minute) and the participants had to report when they began to feel uncomfortably warm. Importantly, the participants rated each colour only once. The results failed to demonstrate any effect of the colour manipulation on participants' responses (though there was a significant order effect with participants' tolerance to higher temperatures building-up over the course of the study). Meanwhile, the 21 participants in a subsequent study by Bennett and Rey (1972) wore goggles with blue, red, or clear lenses. In this case, the participants were required to report on their thermal comfort in rooms with various levels of air-conditioning - wall temperatures were varied from about $60^{\circ} \mathrm{F}$ to $100^{\circ} \mathrm{F}$ and back again. Once again, though, the results failed to provide any clear evidence that colour contributed to the participants' judgements of thermal comfort.

Although there are some inconsistencies and ambiguities, the majority of the psychological research on colour-temperature associations that has been published during the 20th century supported the conclusion that red and yellow are perceived as warmer than green and blue surfaces. For example, Lewinski (1938) and Ross (1938) both reported that projected red colours were rated as warmer than projected blues. Similarly, Tinker (1938) and Newhall (1941) both reported that people consistently described red surfaces (coated papers/cloths in Tinker's study) as warmer than blue surfaces/coated papers/cloths. However, these and other early studies typically failed to separate the effects of hue, from those attributable to brightness and saturation. Wright (1962) and Wright and Rainwater (1962) dealt with this potential issue, in the process demonstrating that the influence of hue on judgements of the apparent warmth of coloured squares was independent of both brightness and saturation. The results of the latter studies also suggested that darker and more saturated colours were generally rated as warmer (see also Kim et al., 
2006, for work isolating hue from value and chroma; and Slobodenyuk et al., 2015).

In another study, Morgan et al. (1975) attempted to explore the developmental onset of the crossmodal correspondence between colour and temperature by exploring any age-related differences in the associations made by children. Their results demonstrated the relatively late development and seemingly fragile nature of the conventional associations between temperature and colour. In total, 36 participants took part in this study, 12 in each of three age groups $(6,12$, and 18 years). The participants were asked which of four colours (blue, green, yellow, or red) they were reminded of when holding containers having one of four temperatures $\left(4,23,35\right.$, or $\left.45^{\circ} \mathrm{C}\right)$. The older age group showed above-chance conventional selection for all four temperatures, namely hot-red, warm-yellow, cool-green, and cold-blue. By contrast, the only consensual mapping amongst the 12 year-olds was hot-red, while at six years of age, the pattern of responding was essentially random (see Marks, 1984, for a similar developmental trajectory in terms of the emergence of the auditory pitch-size crossmodal correspondence). On the basis of their results, Morgan et al. went on to argue that the association between temperatures and colours might be based on cultural norms that are learned only gradually during later childhood and adolescence, and are far from universal, even amongst collegeage participants.

\subsection{Recent Research on Colour-Temperature Correspondences}

More recently, Ho et al. (2014b) provided evidence for the red-warm, bluecold association using a modified version of the implicit association test (IAT). In this task, two response keys are used to respond to target stimuli in a manner that is either compatible or incompatible. The targets in Ho et al.'s first study consisted of colour patches (red or blue) or temperature words ('warm' or 'cold'). The participants $(n=11)$ had to try and discriminate the identity of the unpredictable target (either a colour patch or a word) as rapidly and accurately as possible. In some blocks of trials, the colours and words were associated with the response keys in a congruent manner (i.e., with red and 'warm' being associated with the same response key), while, in the other blocks of trials, the mapping to the response keys was incongruent (see Fig. 1A). The difference in performance between the incongruent and congruent blocks provides a measure of the strength of the association. A significant IAT was observed no matter whether the participants were responding to the colours or to the temperature words (see Fig. 1B).

In a second experiment, temperature-related stimuli (the words 'cold' and 'warm', $n=14$ participants) or actual thermal stimuli delivered by a Peltier heating element $\left(17.3^{\circ} \mathrm{C}\right.$ or $34.2^{\circ} \mathrm{C} ; n=17$ participants), and colour patches were used in a crossmodal priming study involving speeded discrimination. 
(A)

(B)

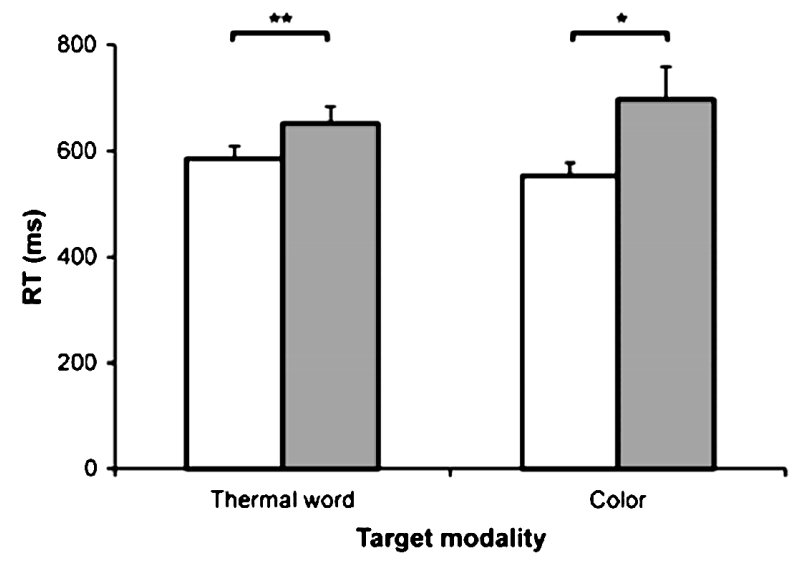

Figure 1. (A) Two of the stimulus-response assignments used in different blocks of trials in Ho et al.'s (2014b; Experiment 1) IAT study. (B) Results showing a significant slowing of participants' responses in the incongruent (gray bars) as compared to congruent blocks of trials (white bars), thus supporting the existence of a 'natural' mapping between colour (red $v s$ blue) and temperature (the words 'warm' and 'cold'). (,$p<0.05$; ${ }^{* *}, p<0.01$.) (Figures reprinted with permission from Ho et al., 2014b.)

In the latter case, though, while the presentation of the colour patches influenced participants' response latencies to subsequently-presented physical thermal targets (in the expected direction), no priming effect whatsoever was demonstrated for any of the other three stimulus combinations. This asymmetrical pattern of results might be taken to argue against the bidirectional nature of colour-temperature crossmodal correspondences. Alternatively, however, 
it may also reflect the fact that the latter three conditions (all involving responses to visual stimuli) had dramatically faster response latencies than when responding to the physical thermal stimuli (c. $550 \mathrm{~ms} v s 2000 \mathrm{~ms}$ ). Whatever the most appropriate explanation for the latter null results, taken together, the two experiments reported by Ho et al. (2014b) clearly support the existence of the crossmodal correspondence between colour (blue $v s$ red) and temperature cues (either indexed by word cues or when delivered as sensory stimuli), at least under the appropriate testing conditions.

Elsewhere, Ho et al. (2014a) had their participants rate the warmth of a redor blue-coloured surface. Intriguingly, in this case, the surface colour results demonstrated a contrast effect (the authors themselves arguing for an explanation in terms of 'anti-Bayesian' integration: "which suggests that the brain integrates direct temperature input with prior expectations about temperature relationship between object and hand in a way that emphasizes the contrast between the two"; Ho et al., 2014a, p. 1), with the blue surface being more likely to be judged as warm than the red surface. The participants in Ho et al.'s first study ( $n=12$ participants) had to hold their hand against a coloured surface whose temperature was gradually increased (or decreased) and indicate the lowest temperature at which the object started to feel warm. The results revealed that the lowest temperature at which the red surface felt warm was significantly higher than for the blue surface (a mean difference of $0.6^{\circ} \mathrm{C}$; see Fig. 2). This means that a blue object was more likely to be judged as warm than was a red object of the same physical temperature. Intriguingly, however, the opposite pattern of results was obtained in a second experiment $(n=11$ participants) in which the colour of the participant's hand was changed instead. In the latter case, the results were consistent with a Bayesian averaging of felt temperature in the direction of the visually-estimated temperature.

It is unclear whether the key difference between these two studies is the difference between the use of non-luminous vs luminous colour, or perhaps the difference between colour being seen on (or associated with) a surface $v s$ on the self. Potentially relevant here, it has been reported that viewing a reddened arm (in virtual reality) decreases a participant's threshold for heat pain, whereas viewing a blueish arm increased the heat pain threshold instead (Martini et al., 2013). One might also be tempted to try and tie the results showing crossmodal assimilation and contrast of colour and temperature cues into the Bayesian framework. However, any simple account of such differing results as 'Bayesian' or 'anti-Bayesian' is probably going to be too simplistic, given that Bayesian models can now account for both types of behaviour (see Wei and Stocker, 2015).

Michael and his colleagues have reported on a number of studies that appeared to demonstrate that participants are biased to report nasal sensations 
(A)

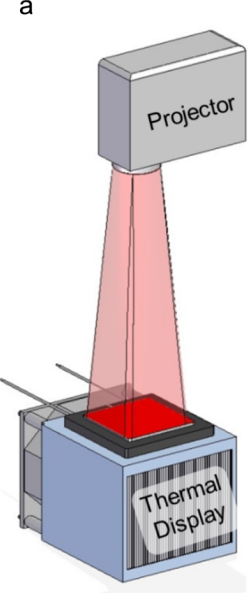

b

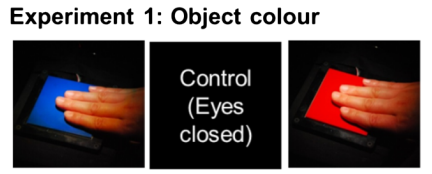

Experiment 2: Hand colour

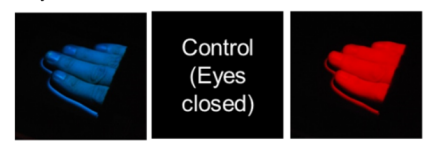

EXP2: Hand colour

(B)

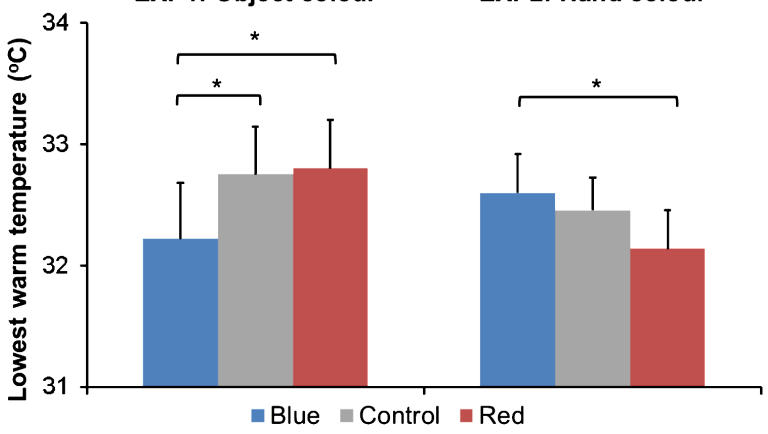

Figure 2. (A) The experimental set-up used by Ho et al. (2014a), allowing for feedback control to the temperature of the touched surface. The colour was manipulated by attaching blue or red colour paper onto the thermal display (Experiment 1), or else by projecting blue or red colour onto the hand that was in contact with the surface (Experiment 2). In both experiments, an eyes-closed control condition was also included. Notice the difference between the use of non-luminous and luminous colour (Experiments 1 and 2, respectively). (B) Results indicating the mean $(+\mathrm{SEM})$ of the lowest warm temperature of the surface. The colour manipulation in Experiments 1 and 2 of Ho et al.'s (2014b) study is indicated by the colour of the bars, with blue, grey, and red bars standing for blue colour, eye-closed control, and red colour, respectively. $n=12$ participants in Experiment 1 , and $n=11$ in Experiment 2$)(*$ denotes $p<0.05$, post hoc Tukey Test). (Figures reprinted with permission from Ho et al., 2014a.)

as warming (rather than cooling) when looking at a red solution (and the olfactory stimulus was presented to their left nostril), whereas they were biased to report cooling if they fixated on a green solution instead (Note 11) and the olfactory stimulus was presented to their right nostril (Michael and Rolhion, 2008; Michael et al., 2010). However, the complex (i.e., nostril-dependent) nature of the results, together with the forced-choice nature of the paradigm 
(under conditions where the olfactory stimulus itself never changed), makes it somewhat uncertain as to whether their findings reflect anything more than a rather convoluted response bias.

Intriguingly, red laser pointers have been reported to give rise to a warm sensation in a proportion of those undergoing the rubber-hand illusion (Durgin et al., 2007). Note here that participants are unable to determine which hand the laser pointer is illuminating with their eyes closed, not to mention the fact that the laser pointer is actually shining on the rubber hand (which obviously cannot feel anything). As such, this clearly shows the consequences of crossmodal colour-temperature correspondences for thermal sensations, at least at the border regions of temperature perception. Meanwhile, elsewhere, Moseley and Arntz (2007) have reported that people rate red thermal laser stimuli as hurting more than blue laser stimuli, despite the fact that the laser heat/pain stimulus was the same in both cases.

\subsection{Temperature-Based Correspondences With Pitch}

Wang and Spence (2017) demonstrated the existence of crossmodal correspondences between temperature (either imagined or physically present) and the auditory stimulus dimensions of pitch and tempo (cf. Eitan and Rothschild, 2011). The participants in their initial study $(n=30)$ were presented with a 5-by-5 array of musical compositions that varied parametrically in terms of both their pitch (from C3 to C7) and tempo (60-380 beats per minute). The participants had to imagine drinking a cold, room-temperature, and hot drink of water, and then pick the soundtrack that matched the imagined thermal sensation. The results revealed that the imagined cold drink was associated with a soundtrack that was higher-pitched (than either other drink) and had a significantly faster tempo than the imagined room-temperature drink. A second experiment in which the participants $(n=24)$ actually tasted hot, room-temperature, and cold water gave rise to a very similar pattern of results.

There are a number of possible environmental statistical relations between temperature and pitch that might underpin such crossmodal correspondences. For instance, Velasco et al. (2013a, b) reported that cold water makes a higher-pitched pouring sound than hot water (due to the temperature-viscosity relation). Another possible source for the pitch-temperature correspondence might be in terms of higher ambient temperature resulting in reduced tension in stringed instruments and hence a lowering of the pitch of sound they make (i.e., they will sound flat; see Tipler and Mosca, 2008). A third natural statistic that might underpin the crossmodal correspondences that have been documented between sound and temperature relates to the absorption of sound by the atmosphere, which jointly depends on frequency, temperature, and humidity (e.g., see Harris, 1967). And, separate from these putative statistical 
accounts, one might also think of height, pitch, high tempo and low temperature as all being linked in terms of their 'alerting' potential (e.g., Van der Zwaag et al., 2011; see also McFarland, 1985).

\subsection{Temperature-Based Correspondences With the Chemical Senses}

Increasing the temperature of food and drink very often tends to be associated with an increase in taste intensity (Bajec et al., 2012; Fleming, 2013; Green, 1992b; McBurney et al., 1973; Olson et al., 1980; Talavera et al., 2007). There is, in other words, a crossmodal correspondence between temperature and taste intensity as well.

At the same time, the colour of plateware and of food have both been shown to influence the rated heat/temperature that people associate with thermally or chemaesthetically hot stimuli (e.g., Suzuki et al., 2017). For instance, Guéguen and Jacob (2012) had 120 French participants taste coffee from blue, green, red, and yellow cups and indicate which coffee was warmest in terms of its temperature. Of the participants, $38 \%$ rated the coffee served in the red cup as the warmest, followed by the coffee served in the yellow (28\%), green (20\%) and, finally, the blue cup (13\%). Suzuki et al. had 12 female participants consume a warm potage soup and rate their sensations of warmth (along with a number of other ratings). The soup was coloured blue, yellow, or white. The results showed that the women's reported thermal sensations were significantly lower after consuming the blue soup along with a trend toward an effect on body temperature as well.

Elsewhere, a crossmodal correspondence has also been reported between chemaesthetically induced heat/temperature, as with the warmth of capsaicin (e.g., in chilli), and the colour red (Shermer and Levitan, 2014; Tu et al., 2016) as well as with sound properties (Wang et al., 2017). So, for example, Shermer and Levitan (2014) demonstrated that people associated the colour red with piquancy. In particular, they reported that the intensity (saturation) of red colouring in a salsa (varied over five levels) affected people's ratings of the expected spiciness of salsas that were viewed on a computer monitor. Increasing the redness (saturation) of the salsa led to a significant increase in the expected piquancy (or heat) of the dish. Subsequently, these researchers went on to demonstrate that expected spiciness exerted a significant influence over the rated level of spiciness on tasting the salsa itself. In particular, the participants in a second experiment tasted a mild and a more piquant salsa having one of two levels of redness when sighted and when blindfolded. For the spicier of the two salsas, the less intensely red one was rated as significantly less piquant that the redder version. However, both blindfolded ratings matched the sighted redder salsa. Intriguingly, though, the change in visual appearance had no effect on ratings of the piquancy of the milder of the two salsas. These results therefore demonstrate that the colour of a food can, at least under certain 
conditions, influence both the expected and perceived spiciness of a dish, providing that it is already moderately spicy. Elsewhere, Tu et al. (2016) reported a study showing that people rate spicy tofu as tasting as much as $20 \%$ spicier when served off a red plate than when sampled from a white plate instead.

Wang et al. (2017) explored the sound-chemaesthetic heat correspondence, by establishing the auditory parameters that people match with the heat of chilli peppers - namely higher pitch, faster tempo, and a distorted timbre. Playing a spicy soundtrack (in the lab or in a restaurant) biased people's judgements of the heat associated with a spicy food/salsa. And, once again, high arousal would appear to be a common link connecting the various stimuli in this case (see Spence, 2018b). Returning to the more general question of touch-/haptic-based correspondences, of all the touch-/haptic-based correspondences that have been documented to date, those involving temperature appear different from others such as weight, hardness, roughness (Jraissati and Wright, 2018). In particular, while temperature-based correspondences appear to be based on hue, the other tactile/haptic correspondences that have been studied to date tend to be based on lightness/brightness (and to a lesser extent saturation) instead (cf. Asad et al., 2016).

Certain crossmodal correspondences are relative phenomena (see Spence, 2019b, for a review; Asad et al., 2016). At the same time, however, it would appear that judgements of what counts as warm/hot or cold are made with reference to the observers themselves. Note here also the categorical nature of hue means that such metathetic mappings are more absolute. This observation, of course, does not deny the possibility that relative colour-temperature correspondences cannot also be found - think only of how the redder of two colours will presumably be matched with the higher of two temperatures (i.e., prothetic correspondences are also likely to operate in this space). That said, the wavelength of light is also a prothetic physical dimension adding a layer of complexity to matters (see also Wright et al., 2017).

At this point, it is probably worth clarifying metathetic and prothetic, as these are terms that are not widely used. The distinction here originates with Stevens (1957, p. 154). He highlighted a distinction between two kinds of perceptual continua, namely prothetic (magnitude) and metathetic (qualitative). The former is concerned with continua that are related to quantity (i.e., how much), while the latter describes continua where the stimuli are arranged in qualitative terms (i.e., what kind or where). For example, loudness, size, duration, and rate of change all constitute prothetic dimensions with clear 'more than' (e.g., loud, bright, big) and 'less than' ends (e.g., quiet, dark, small; Walsh, 2003). Prothetic continua can, then, be thought of as one class of polar correspondence, just with the poles set at 'more than' and 'less than'. By contrast, pitch constitutes a metathetic dimension, since a high-pitched tone 
is different in kind from a low-pitched tone, without necessarily being meaningfully related in a more than/less than manner (shape is also metathetic; see Smith and Sera, 1992). Note, the exact correspondence between these two classes of continua and their underlying neural representations still remains to be elucidated (Lewkowicz and Turkewitz, 1980; Stevens, 1971). In adults, prothetic dimensions tend to possess a unitary and well-ordered psychophysics, while metathetic dimensions do not. Adding to the uncertainty in this area is the fact that colour and pitch can also be organized in a circular manner (Gilbert et al., 2016; Spence, 2020).

Relevant to the more cognitive associations that people have with colour, it is worth considering 'colour in context' theory (e.g., see Elliott and Maier, 2012, 2014). According to the latter account, the meaning of colour often varies depending on the context in which it is encountered. In the context of the colour associations with basic taste (i.e., bitter, sweet, salty, and sour), the colour red is strongly associated with sweetness (see Spence, 2019b; Spence et $a l ., 2015$, for reviews). However, red is also associated with hot and spicy food (see Guéguen and Jacob, 2012; Shermer and Levitan 2014; Spence, 2018b). Elsewhere, in context (e.g., at school) red may be associated with failure instead (Lichtenfeld et al., 2009). There are, in other words, many more-or-less strongly associated concepts with any specific colour (hue). It is likely, therefore, that the context will determine the conceptual crossmodal associations that are likely going to be foregrounded in any given experimental situation (see Schietecat et al., 2018a, b).

One might legitimately want to know whether effects involving temperature operate at the explicit and/or implicit levels. This question is links to the question of whether crossmodal correspondences are more automatic or task-dependent (see Getz and Kubovy, 2018; Spence and Deroy, 2013). With regards to the latter issue, crossmodal correspondences appear to exhibit some, but by no means all, characteristic features of automaticity. What is more, the explicit links identified in language may also influence performance. At the same time, however, there is also evidence of implicit correspondences from research using the IAT that is also context-dependent (see below).

\section{Colour-Based Influences on Thermal Comfort}

Greene and Bell (1980) assessed the impact of 'warm' and 'cool' wall colours on energy conservation. They tested 144 students in carrels (i.e., small cubicles) having one of three wall colours (white, red, or blue) and four ambient temperatures $\left(18,22,29\right.$, and $\left.35^{\circ} \mathrm{C}\right)$. The participants had to perform a 5-min filler task before rating their personal comfort, perceived ambient temperature, and arousal. While colour influenced ratings of personal comfort, and perceived environment quality, there was no observable effect on perceived 


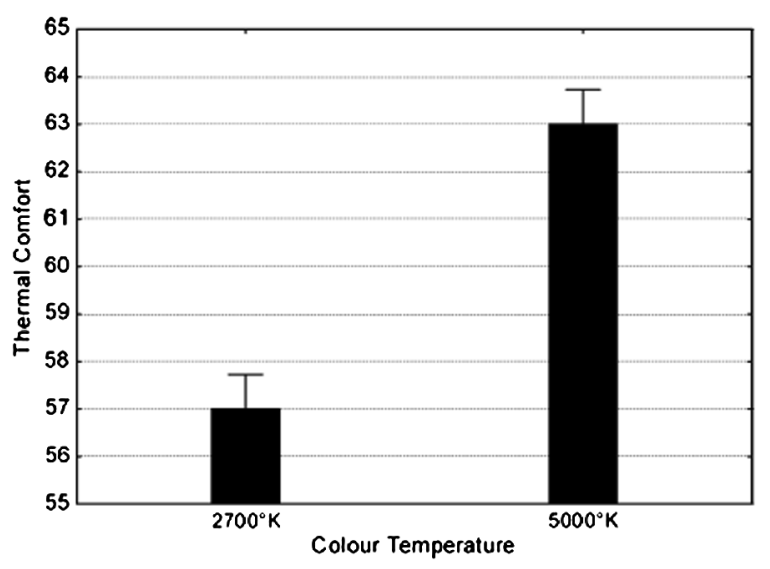

Figure 3. Mean thermal comfort ranking on a 0 (very uncomfortable) -100 (very comfortable) scale, as a function of colour temperature $(2700 \mathrm{~K}$ and $5000 \mathrm{~K})$ obtained with different fluorescent lamps in an unpublished study reported by Candas and Dufour (2005). The results highlight a significant effect of the colour of the lighting on thermal comfort. (Figure reprinted from Candas and Dufour, 2005.)

temperature. Meanwhile, in an unpublished study reported by Candas and Dufour (2005), these researchers attempted to demonstrate the effect of colour temperature on thermal comfort. Forty-eight participants were subjected to two levels of colour temperature [2700 K 'warm colours' (yellowish) and $5000 \mathrm{~K}$ 'cool colour' (blue-ish)] for two hours in what was described as a slightly warm environment. The participants had to rate their thermal comfort. The results revealed a small but significant increase in thermal comfort for the participants when exposed to the $5000 \mathrm{~K}$ lighting (see Fig. 3).

One of the implications of colour-temperature correspondence research concerns the possibility that ambient colour could be used to influence the perceived temperature of indoor environments (e.g., Faulkner, 1972; Greene and Bell, 1980; Winzen et al., 2014). Along just these lines, Winzen et al. suggested that colour could be used as a means of energy conservation (Note 12) in the air, but others have had the same idea on the ground as well. The latter researchers assessed the impact of coloured light on the thermal comfort of participants in a mock-up aircraft cabin. There were four conditions in the study, roughly counterbalanced, with two blues and two yellows (with centroid wavelengths of 603 and $607 \mathrm{~nm}$ for the yellow lights, and 497 and $505 \mathrm{~nm}$ for the blue lights). There were six sessions with ten participants (bar one session with only nine; i.e., $n=59$ in total), in a room at $22.2^{\circ} \mathrm{C}$. The hypothesis was that yellow light would create a perception of a warmer temperature, while blue light would elicit a perception of a cooler temperature. The participants were exposed to each of the four coloured lighting environments for nine minutes. They had to make a number of perceptual judgements including rating 


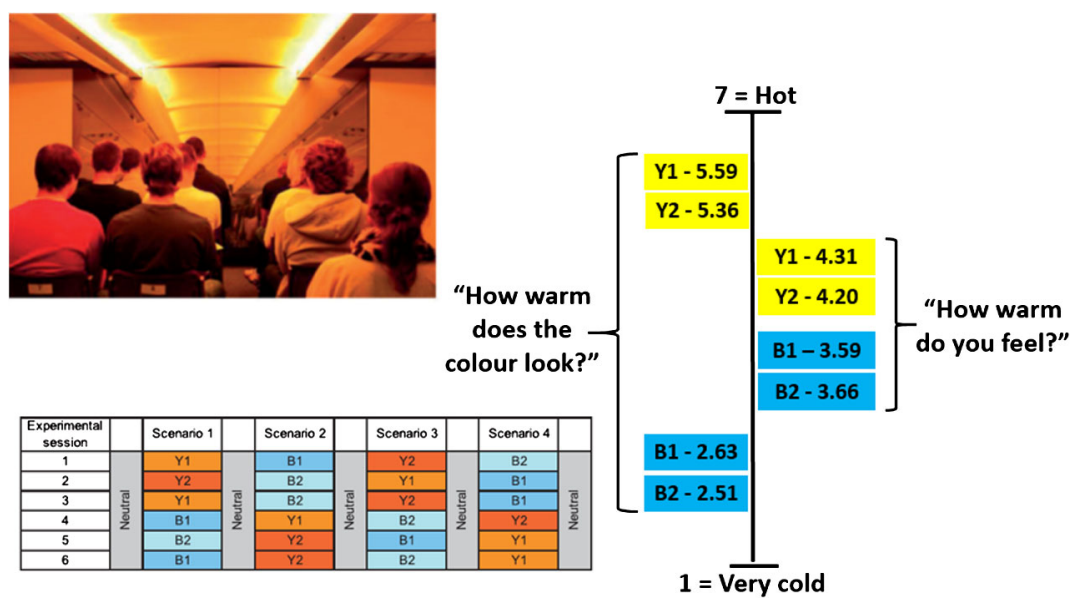

Figure 4. The simulated cabin used to test the participants in Winzen et al.'s (2014) study of the impact of coloured lighting on thermal comfort. The experimental design (involving groups of 10 participants being exposed to two yellow (Y1 and Y2), and two blueish lighting conditions (B1 and B2)) is shown together with the results obtained on the two scales (not shown to scale) that were presented one after the other, thus potentially leading to some sort of biasing (or anchoring) effect.

the perceived warmth of the colours. Thereafter, they had to make a number of thermal comfort judgements including one for temperature. The perception of room temperature was rated on a seven-point scale (from $1=$ very cold to $7=$ hot; see Fig. 4). The results demonstrated a significant impact of the colour of the lighting on people's perception of the temperature of the simulated cabin. One potential limitation with the interpretation of this study, though, is the possibility of end anchoring (Epley and Gilovich, 2001; Stewart, 2009; Tversky and Kahneman, 1973), given that the participants first rated the warmth of the colour before rating their own thermal warmth. In particular, their first visual rating may have influenced their subsequent thermal rating.

\section{Multisensory Modulation of Temperature Perception}

Having demonstrated the existence, and consequences, of crossmodal correspondences involving different pairs of sensory modalities, the next question becomes one of whether these various cues can be combined in order to elicit a more dramatic impact on the feeling, or perception, of temperature or warmth. In part, this was the idea behind a study reported by Sester et al. (2013) in which dynamic visual and auditory cues to warmth $v s$ cold were incorporated into a bar environment in order to assess whether the semantic cues to temperature would bias people's choice when it came to ordering a drink (see also Kanaya et al., 2012). The warm environment had wood furniture and warm 


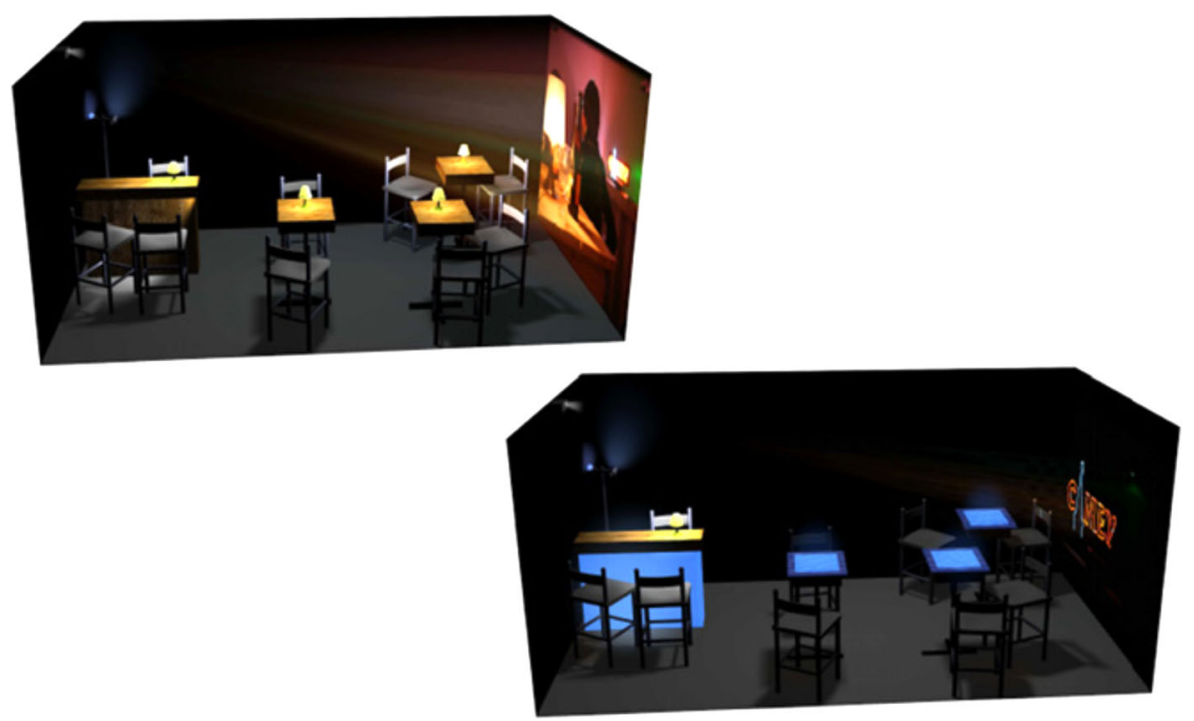

Figure 5. 3D representations of the immersive bars: (a) Warm setting; (b) cold setting, from Sester et al. (2013).

colours/audiovisual clips (e.g., video of hot desert scene), whereas the cold environment had blue furniture and videos of icebergs etc. (see Fig. 5). The results demonstrated that people chose difference drinks (think cocktail or iced tea) when in the warm environment than when in the cold environment (where, put simply, warming drinks such as tea/coffee/hot chocolate were chosen more often).

Elsewhere, Takakura et al. (2015) have demonstrated that viewing videos of hot $v s$ cold scenes (see Fig. 6A) can exert a small but significant effect on body temperature (as assessed by a rectal probe inserted a not inconsiderable $13 \mathrm{~cm}$ ). That said, the effects were slow-acting (see Fig. 6B), and what is more, the participants' reports suggested that they themselves were not consciously aware of change (see Fig. 6C).

In recent years, there has been growing interest amongst a number of marketing-minded researchers in trying to understand the influence of changes in ambient temperature on consumer decision-making. Relevant here, Motoki et al. (2019) investigated the effects of light colours and comfortable warmth, in the process demonstrating that crossmodal correspondences between thermal sensations and colour lightness influenced consumer behaviour. In particular, in one of their experiments these researchers demonstrated that physical warmth increased the visual attention directed toward light-coloured goods.

A number of multisensory studies have combined various sensory cues such as colour with noise though, once again, the results have been mixed (e.g., 
(A)

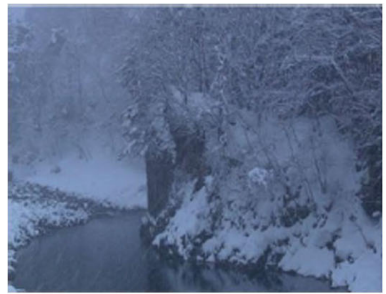

Cold image

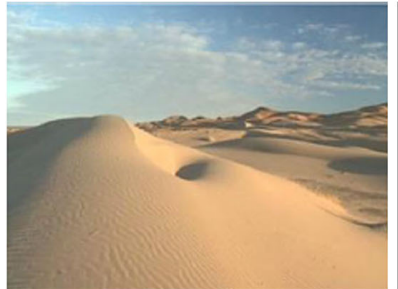

Hot image

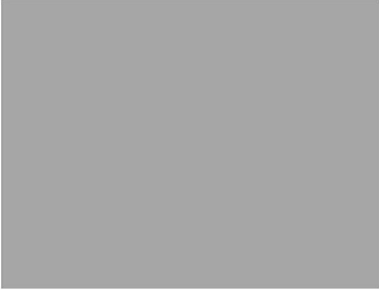

Control image

(B)

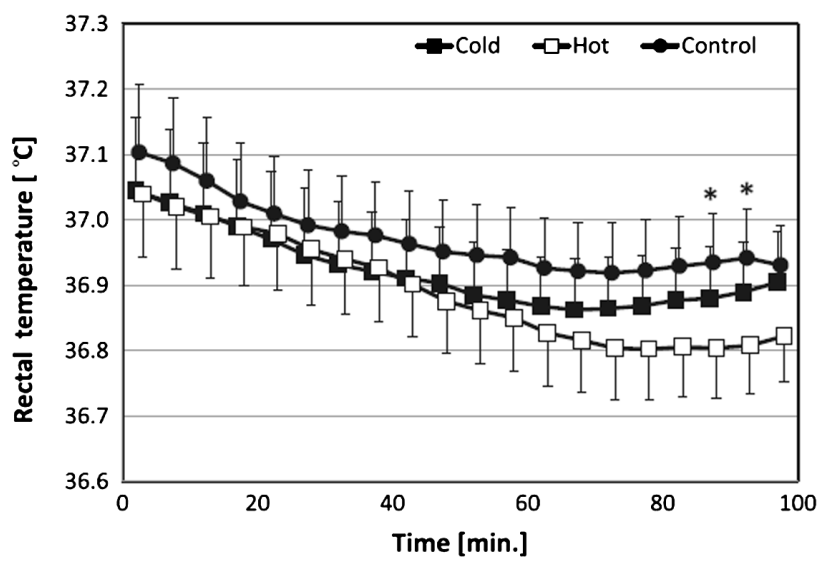

(C)

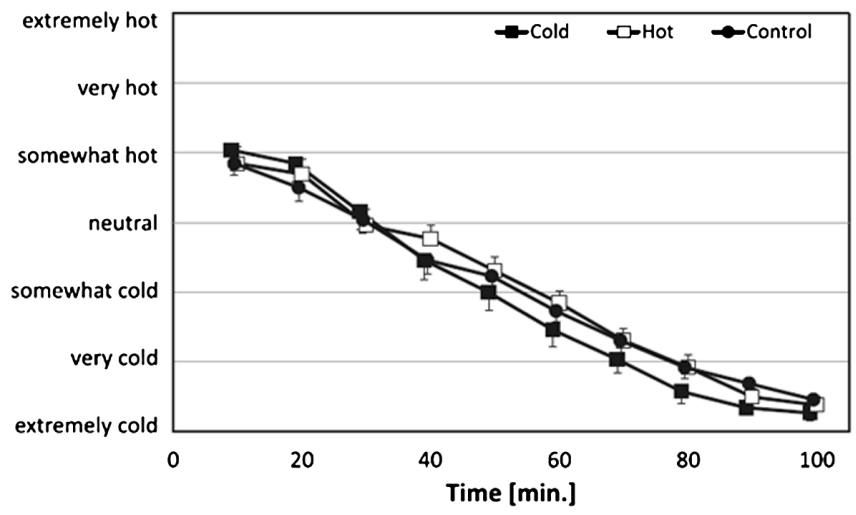

Figure 6. (A) Still images from the hot and cold conditions used in Takakura et al.'s (2015) study. (B) Temporal course of rectal temperature. Plot values are indicated as means \pm standard errors. ${ }^{*}, p<0.05$ for control versus hot $(n=11)$. (C) Thermal sensation scores rated every $10 \mathrm{~min}$. Plot values are indicated as mean \pm standard errors. No significant differences were found between video image conditions $(n=13)$. (Figures reprinted from Takakura et al., 2015.) 
Fanger et al., 1977; Landgrebe et al., 2008; Matsubara et al., 2004; Pellerin and Candas, 2003). For instance, in one intriguing study on thermal comfort, Fanger et al. exposed eight males and eight females to either extreme red (with a distribution peaking at c. $650 \mathrm{~nm}$ ) or extreme blue lighting (with a distribution peaking at c. $400 \mathrm{~nm} ; 190 \mathrm{vs} 150$ lux, respectively), and to one of two levels of white noise [ 40 or $85 \mathrm{~dB}(\mathrm{~A})$ noise]. In each of the four experiments (lasting $2 \frac{1}{2}$ hours), the preferred ambient temperature was determined by adjusting the actual ambient temperature in line with the participant's wishes. The results revealed that the participants did indeed prefer a slightly, but significantly, lower $\left(0.4^{\circ} \mathrm{C}\right)$ ambient temperature in the extreme red, as compared to the extreme blue, lighting condition. By contrast, the noise manipulation had no observable impact on the pattern of results obtained, nor did anything show up in terms of the physiological measures in response to the coloured lighting (skin temperature, rectal temperature, and evaporative weight loss).

Elsewhere, Kearney (1966) reported a study showing that changes in ambient temperature can influence people's colour preferences. In particular, the participants in the latter study were placed in an environment that was maintained at one of three temperatures: hot $\left(37-43^{\circ} \mathrm{C}\right)$, cool $\left(15-17^{\circ} \mathrm{C}\right)$, or cold $\left(-5-0^{\circ} \mathrm{C}\right)$. The colour of the lighting was varied too, being either red $(640 \mathrm{~nm})$, yellow $(580 \mathrm{~nm})$, green $(530 \mathrm{~nm})$, or blue $(460 \mathrm{~nm})$. When the ambient temperature was hot, people's colour preferences were inversely related to the wavelength, whereas in the cold environment, colour preferences correlated with the wavelength instead. Thus, when the ambient temperature was cold, the participants liked (or showed a preference for) red, whereas when the environment was hot, they preferred blue/green instead. (Note that there were also three lightness levels but this variable had no effect on the pattern of results reported.)

Taken together, the results reported in this section reveal that the colour of ambient lighting does indeed have a small but significant effect on thermal comfort/temperature perception (Candas and Dufour, 2005; Fanger et al., 1977; Winzen et al., 2014). That said, researchers appear to disagree on how relevant/salient such differences might be. For instance, on the basis of their results, Fanger et al. (1977, p. 11) were minded to conclude that: "The effect of colour on man's comfort is, however, so small that it has hardly any practical significance". And while the $0.4-0.6^{\circ} \mathrm{C}$ changes in temperature reported in studies such as Fanger et al. (1977) might seem small, numerically-speaking, it is worth noting that given the warmth detection threshold $\left(0.2^{\circ} \mathrm{C}\right)$ and the thermal discrimination threshold $\left(0.03-0.09^{\circ} \mathrm{C}\right.$; Johnson et al., 1979; Stevens and Choo, 1998) such changes in temperature are of a magnitude that would clearly be perceptible to participants under the appropriate conditions.

As visual inspection of Table 1 makes clear, the ranges of temperature that have been studied in previous colour-temperature research have varied widely. 
As such, one might wonder whether careful and systematic analysis of the nature of stimulation in the natural environment (cf. Parise et al., 2014) might not reveal different relationships between colour and temperature at different points on the range of temperatures that humans can easily (or comfortably) be exposed to.

\section{Explaining Colour's Effect on Thermal Comfort/Temperature (Perception)}

At this point, it is interesting to speculate on the mechanism underlying coloured light's impact on thermal comfort, and hence presumably also on body temperature (when such effects have been documented). As mentioned earlier, temperature is an especially interesting dimension of tactile experience given that we have a feeling both about the temperature of our own body and the temperature of the environment, as well as the objects that we come into contact with. There is a social dimension to warmth too (as when we describe a person as 'warm'; see MacRae et al., 2013, on the link to the more social aspects of warmth). Thermal sensation is thought to involve various different cortical and subcortical regions (Casey et al., 1994). Temperature regulation is required on a daily basis when the body heat is out of balance (Candas and Dufour, 2005). If the temperature disequilibrium is large then metabolically costly physiological responses such as shivering or voluntary heat production may be involved: Our metabolism increases when we are cold, while sweating may be triggered when we are too hot. Should the temperature imbalance be small then physiological adjustments such as vasoconstriction or vasodilatation enable us to redistribute heat within the body without the physiological costs being so high (see Tattersall et al., 2012). To date there has been only very limited evidence published documenting the existence of thermoreceptive multisensory neurons involved in temperature perception (Dong et al., 1994).

Further complicating matters, one important modulatory factor here influencing coloured lighting's crossmodal effects relates to circadian rhythms (Reppert and Weaver, 2002), and in particular, the well-documented impact that short-wavelength blue light has on setting the internal clock (Lockley et al., 2006; Morita and Tokura, 1995; Souman et al., 2017). It turns out that we are more influenced by such light at the end of the day, when ambient light levels are normally low (e.g., Cajochen et al., 2005; see also Khalsa et al., 2003). For instance, French et al. (1990) demonstrated that exposure to bright light (3000 vs 100 lux) led to an increase in body temperature (assessed sublingually) of a little under $1^{\circ} \mathrm{F}$ (during the night-time hours, 21.30-03.30; see also Badia et al., 1991). Such circadian factors might perhaps predict that the influence of lighting colour on temperature perception may only be observed 
at certain times of day, or rather, at certain points in the circadian cycle (see Morita et al., 1995). Cajochen et al. (2005) demonstrated that short wavelength monochromatic light at $460 \mathrm{~nm}$, when presented for two hours in the late evening (from $9.40 \mathrm{pm}$ ) led to melatonin suppression, greater alertness, and an increase in core body temperature of c. $0.1^{\circ} \mathrm{C}$ (leading to a significant difference in the distal-proximal skin temperature gradient) when compared to two-hour exposure at $550 \mathrm{~nm}$ light (or no light exposure) instead. That said, while such thermophysiological coloured-light-induced changes in core body temperature are significant, as has been highlighted already, they are likely to have been too small to be consciously perceptible by the participants who took part in these studies, hence challenging the suggestion of this crossmodal connection as the natural statistical underpinning this crossmodal correspondence.

\section{Conclusions}

The research that has been published to date clearly demonstrates the existence of a number of crossmodal correspondences with the temperature dimension. While the majority of this research has tended to focus on those correspondences with warm and cold colours (Ho et al., 2014b), as has been noted here, crossmodal correspondences with sound properties, such as pitch and tempo, have also been documented (see Eitan and Rothschild, 2011; Velasco et al., 2013a, b; Wang and Spence, 2017). Intriguingly, the research shows that these correspondences influence people's performance in behavioural tasks, such as the IAT and, on occasion, crossmodal priming tasks as well (see Ho et al., $2014 a, b)$. There is also a long history of published studies showing that exposing people to different colours can sometimes influence their perception of the warmth of coloured surfaces, objects, food and drink, and even the thermal comfort of the environments in which they happen to find themselves (see also Takakura et al., 2013, 2015). It should, though, be noted that thermal comfort and pleasantness are by no means synonymous terms (Kwon and Parsons, 2008).

The studies reviewed in this manuscript have relied on a wide range of experimental paradigms, stimuli, and dependent variables (e.g., see Table 1 for a partial summary). For instance, in some studies the thermal stimuli were physically present, while in others merely imagined, or again, the dependent variables varied from behavioural responses (of many different types, from reaction times, to thermal comfort ratings, etc.) to physiological responses (e.g., body temperature in various guises). Obviously, different techniques and dependent variables are likely going to measure different aspects of the same phenomenon (if not different phenomena altogether). It is worth bearing in 
mind here that such methodological differences might help to explain some of the possible inconsistencies across different studies.

In conclusion, while there would undoubtedly appear to be some thermophysiological effects of coloured lighting, particularly at the short wavelength end of the spectrum (centred on the $460 \mathrm{~nm}$ blue light of dawn), many of the effects that have been reported in the literature would seem to be of a rather more cognitive/psychological nature instead. Such conventional colourtemperature associations may, then, result in a behavioural pattern of responses that is more consistent with assimilation (Fanger et al., 1977; Ho et al., 2014a, Experiment 2; Winzen et al., 2014) or else, on occasion, contrast (see Ho et al., 2014a, Experiment 1; Mogensen and English, 1926).

Returning, now, to the four broad classes of crossmodal correspondence outlined earlier, one can ask how the various colour-based correspondences fit into the framework of statistical, structural, semantic, and affective correspondences. While this issue has been discussed to a certain extent already, in summary, it would seem as though all four accounts likely play some role in helping to explain colour-temperature correspondences. It is clear that affective responses are generated in response to both colour and temperature and hence might sometimes provide a basis for a crossmodal match. However, it is equally clear that the semantic/linguistic account might well play some small role, though 'red hot' is the only crossmodal metaphor that immediately springs to mind. It is also worth bearing in mind here, as noted by Spence (2011), that semantic correspondences might well build on the statistical relationships that are present in the environment. In terms of innate correspondences, the magnitude-based account appears to operate with temperature stimuli when the visual saturation and lightness are not carefully controlled, as was often the case in early studies. However, as to whether such a mapping builds on a putatively innate magnitude mapping or, instead, whether it is acquired as a result of statistical learning of environmental regularities is, as yet, unclear. At the same time, however, it is worth remembering that hue-temperature correspondences appear to be acquired during development (Morgan et al., 1975).

\section{Application}

There are several potential areas where the findings concerning colourtemperature correspondences might be used. One potential application that has excited researchers in terms of the potential implications is helping to reduce energy costs, should the consequences of the correspondences on thermal comfort turn out to be long-lasting (see also Takakura et al., 2015; Winzen et al., 2014). At the same time, however, some researchers have used more semantically meaningful audiovisual cues to temperature (e.g., images of videos 
associated with hot or cold scenes; see Sester et al., 2013; Takakura et al., $2013,2015)$ in order to bias people's thermal perception. It is, though, important to stress, as many researchers have noted previously, that the effects on temperature perception tend to be pretty modest at best and hence the real-world relevance has yet to be convincingly demonstrated. What is more, coloured lighting appears to work better than colouring the walls (though see Telegraph Reporters, 2019, for the results of a recent study suggesting that wall colour can also impact thermal comfort/temperature perception under certain contrived conditions), although colour constancy can potentially work against the effects of coloured lighting (see Greene and Bell, 1980). Ultimately, therefore, the potential energy-saving value of the hue-heat hypothesis would still benefit from additional empirical support. It is also important to note that strongly coloured environments may affect other aspects of emotional wellbeing (Evans, 2001), and hence thermal comfort is only one issue to consider here.

One of the other long-term hopes for some researchers is that by gaining a better understanding of the nature and robustness of crossmodal correspondences involving tactile stimuli, such as those natural correspondences with temperature, it may be possible to design more intuitive sensory-substitution systems for those who are, e.g., blind (see Hamilton-Fletcher and Ward, 2013). Given the fact that so many people already talk in terms of colour temperature, one might have predicted this would be an especially intuitive mapping for substitution devices (Note 13). At the same time, however, it is important to note that there are both technical and cognitive/physiological constraints on the delivery of thermal stimuli. In particular, the spatial discriminability of thermal stimulation on the skin surface tends to be poor, at least when compared to thresholds for other classes of tactile stimuli (e.g., Gallace and Spence, 2014; Weinstein, 1968). What is more, the temporal rate at which thermal stimuli can be presented and modified is also quite limited currently. Both of these factors might well be expected to hinder the incorporation of temperature-colour correspondences into sensory-substitution devices (cf. Asad et al., 2016). That said, on the other hand, it is also true that it is easier to render realistic temperature cues using technology (e.g., Peltier-type devices) than it is to simulate a variety of other dimensions of tactile experience (such as stickiness, or fine surface texture), with a high level of perceptual realism (see Lin and Otaduy, 2008).

Another important area of application for temperature-based crossmodal correspondences is in virtual and augmented reality (see Gallace, Ngo, Sulaitis and Spence, 2012). Thermal information is complex to render in consumer virtual reality, with thermoelectric devices being both slow and power-hungry ( $\mathrm{Li}$ et al., 2017; Ranasinghe et al., 2017). It would therefore be tempting to pursue the potential use of crossmodal correspondences (e.g., Winzen et al., 2014), as 
well as more semantic types of priming (Petit and Sieffermann, 2007; Sester et al., 2013; Takakura et al., 2015) to try and convey thermal information using other senses. Ultimately, then, developing a better understanding of those crossmodal correspondences involving the temperature dimension may have both practical as well as theoretical importance, and help broaden our understanding of the limits on the crossmodal correspondences more generally.

\section{Notes}

1. The synaesthetic artist, Kandinsky (1977, p. 45) noted in his work Concerning the spiritual in art, especially in painting that some colours are described, in a tactile sense, as rough or prickly, while others are smooth and velvety.

2. Slobodenyuk et al. (2015) showed that qualitatively different virtual haptic sensations (roughness/smoothness, hardness/softness, heaviness/lightness, elasticity/inelasticity, and adhesiveness/nonadhesiveness) were associated with colour (participants were able to pick any colour in CIE $L^{*} a^{*} b$ colour space). Consistent with the results of other studies on crossmodal associations with colour, a strong relationship was documented between the brightness of the visual stimuli and the intensity of haptic stimuli across all of the haptic sensations tested. Specifically, the most intense haptic sensations were associated with the colour choices of the lowest brightness. In other words, the heaviest, the roughest, the hardest, the most inelastic, and the most adhesive stimuli were the least bright. Brightness increased as heavy stimuli became lighter, rough stimuli became smoother, hard stimuli became softer, inelastic stimuli became more elastic, and adhesive stimuli became less adhesive. According to the authors, one suggestion here is that the prothetic intensity dimension may underpin these visual-haptic correspondences.

3. Note that there appears to be little cross-cultural consistency in terms of people's descriptions of smells as being either hot or cold (see Wnuk et al., 2017).

4. The fact that colour-temperature correspondences have also been documented in bees (Dyer et al., 2006) rules out the linguistic account as a necessary contributor to the existence of such crossmodal correspondences.

5. Meanwhile, according to Walker et al. (2010), wet objects tend to be darker and heavier than dry ones, hence perhaps explaining the brightness-weight crossmodal correspondence (Walker et al., 2017). 
6. Note here the fact that our own skin/appearance tends to becomes more bluish when we are cold while becoming redder when we are aroused/hot as a result of vasodilation (Changizi et al., 2006; Ho et al., 2014a).

7. Indeed, over the years, the colour-temperature association (e.g., warmred) had been demonstrated with a diverse set of objects that includes everything from scarves to breakfast trays (see Fenko et al., 2010).

8. Should such a dissociation be found to be reliable, then it might be taken to support a distinction between the existence of a crossmodal correspondence between colour and temperature on the one hand and the absence of any crossmodal influence on the other.

9. It is worth noting that the effects of luminous and non-luminous colours may differ in important ways. Luminous blue, the colour of dawn, is commonly-considered arousing, whereas non-luminous, or reflective, blue is supposedly calming instead (see Gage, 1999; Gulak, 1991).

10. That said, Ho et al. (2014a) did subsequently analyse Mogensen and English's (1926) results statistically with a repeated-measures ANOVA and found a significant effect of colour, with green and blue being significantly warmer than purple ( $p<0.01$, Bonferroni-corrected for multiple pairwise comparisons).

11. The suggestion being that the participants might have been associating mint with green, hence expecting a trigeminal menthol cooling (Labbe $e t$ al., 2008; Nagata et al., 2005). That said, a different association emerges from Ho et al.'s (2014a, p. 3) study, where the authors suggest that “... fire and sun are warm; hence red and yellow are the colours of warmth. Oceans and forests are cool; hence blue and green are the colour of coolness."

12. This is known as the 'hue-heat hypothesis'.

13. Assuming, of course, that the congenitally blind experience the same intuitive mapping between colour and temperature (cf. Saysani, 2019).

\section{References}

Arnheim, R. (1954). Art and Visual Perception: A Psychology of the Creative Eye. University of California Press, Berkeley, CA, USA.

Asad, J., Spiller, M. J. and Jonas, C. (2016). Auditory and visual crossmodal correspondences with haptically perceived liquid viscosity, Multisens. Res. 29, 727-747.

Badia, P., Myers, B., Boecker, M., Culpepper, J. and Harsh, J. R. (1991). Bright light effects on body temperature, alertness, EEG and behavior, Physiol. Behav. 50, 583-588. 
Bajec, M. R., Pickering, G. J. and DeCourville, N. (2012). Influence of stimulus temperature on orosensory perception and variation with taste phenotype, Chemosens. Percept. 5, 243-265.

Bennett, C. A. and Rey, P. (1972). What's so hot about red?, Hum. Fact. 14, 149-154.

Berry, P. C. (1961). Effects of colored illumination upon perceived temperature, J. Appl. Psychol. 45, 248-250.

Biggs, L., Juravle, G. and Spence, C. (2016). Haptic exploration of plateware alters the perceived texture and taste of food, Food Qual. Pref. 50, 129-134.

Bond, B. and Stevens, S. S. (1969). Cross-modality matching of brightness to loudness by 5-year-olds, Percept. Psychophys. 6, 337-339.

Cabanac, M. (1969). Plaisir ou deplaisir de la sensation thermique et homeothermie, Physiol. Behav. 4, 359-364.

Cajochen, C., Münch, M., Kobialka, S., Kräuchi, K., Steiner, R., Oelhafen, P., Orgül, S. and Wirz-Justice, A. (2005). High sensitivity of human melatonin, alertness, thermoregulation, and heart rate to short wavelength light, J. Clin. Endocrinol. Metab. 90, 1311-1316.

Candas, V. and Dufour, A. (2005). Thermal comfort: multisensory interactions?, J. Physiol. Anthropol. 24, 33-36.

Carvalho, F. M., Moksunova, V. and Spence, C. (in press). Cup texture influences taste and tactile judgments in the evaluation of specialty coffee, Food Qual. Pref. 81, 103841. DOI:10. 1016/j.foodqual.2019.103841.

Casey, K. L., Minoshima, S., Berger, K. L., Koeppe, R. A., Morrow, T. J. and Frey, K. A. (1994). Positron emission tomographic analysis of cerebral structures activated specifically by repetitive noxious heat stimuli, J. Neurophysiol. 71, 802-807.

Chabris, C. F., Heck, P. R., Mandart, J., Benjamin, D. J. and Simons, D. J. (2019). No evidence that experiencing physical warmth promotes interpersonal warmth: two failures to replicate Williams and Bargh (2008), Soc. Psychol. 50, 127-132.

Changizi, M. A., Zhang, Q. and Shimojo, S. (2006). Bare skin, blood and the evolution of primate colour vision, Biol. Lett. 2, 217-221.

Chen, Y.-C. and Spence, C. (2017). Assessing the role of the 'unity assumption' on multisensory integration: a review, Front. Psychol. 8, 445. DOI:10.3389/fpsyg.2017.00445.

Collins, J. F. (1965). The colour temperature of daylight, Br. J. Appl. Phys. 16, 527-532.

Craig, A. D. (2002). How do you feel? Interoception: the sense of the physiological condition of the body, Nat. Rev. Neurosc. 3, 655-666.

Demattè, M. L., Sanabria, D. and Spence, C. (2006). Cross-modal associations between odors and colors, Chem. Sens. 31, 531-538.

Deroy, O. and Spence, C. (2013). Why we are not all synesthetes (not even weakly so), Psychon. Bull. Rev. 20, 643-664.

Deroy, O., Fasiello, I., Hayward, V. and Auvray, M. (2016). Differentiated audio-tactile correspondences in sighted and blind individuals, J. Exp. Psychol. Hum. Percept. Perform. 42, 1204-1214.

Deroy, O., Fernandez-Prieto, I., Navarra, J. and Spence, C. (2018). Unravelling the paradox of spatial pitch, in: Spatial Biases in Perception and Cognition, T. L. Hubbard (Ed.), pp. 77-93. Cambridge University Press, Cambridge, UK.

Divard, R. and Urien, B. (2001). Le consommateur vit dans un monde en couleurs, Rech. Appl. Mark. 16, 3-24. 
Dong, W. K., Chudler, E. H., Sugiyama, K., Roberts, V. J. and Hayashi, T. (1994). Somatosensory, multisensory, and task-related neurons in cortical area $7 \mathrm{~b}(\mathrm{PF})$ of unanesthetized monkeys, J. Neurophysiol. 72, 542-564.

Durgin, F. H., Evans, L., Dunphy, N., Klostermann, S. and Simmons, K. (2007). Rubber hands feel the touch of light, Psychol. Sci. 18, 152-157.

Dyer, A. G., Whitney, H. M., Arnold, S. E. J., Glover, B. J. and Chittka, L. (2006). Bees associate warmth with floral colour, Nature 442, 525. DOI:10.1038/442525a.

Eitan, Z. and Rothschild, I. (2011). How music touches: musical parameters and listeners' audio-tactile metaphorical mappings, Psychol. Music 39, 449-467.

Elliott, A. J. (2019). A historically based review of empirical work on color and psychological functioning: content, methods, and recommendations for future research, Rev. Gen. Psychol. 23, 177-200.

Elliot, A. J. and Maier, M. A. (2012). Chapter two - color-in-context theory, Adv. Exp. Soc. Psychol. 45, 61-125.

Elliott, A. J. and Maier, M. A. (2014). Color psychology: effects of perceiving color on psychological functioning in humans, Annu. Rev. Psychol. 65, 95-120.

Epley, N. and Gilovich, T. (2001). Putting adjustment back in the anchoring, and adjustment heuristic: differential processing of self-generated and experimenter-provided anchors, Psychol. Sci. 12, 391-396.

Ernst, M. O. (2007). Learning to integrate arbitrary signals from vision and touch, J. Vis. 7, 7. DOI:10.1167/7.5.7.

Essick, G. K., McGlone, F., Dancer, C., Fabricant, D., Ragin, Y., Phillips, N., Jones, T. and Guest, S. (2010). Quantitative assessment of pleasant touch, Neurosci. Biobehav. Rev. 34, 192-203.

Etzi, R., Spence, C. and Gallace, A. (2014). Textures that we like to touch: an experimental study of aesthetic preferences for tactile stimuli, Consc. Cogn. 29, 178-188.

Etzi, R., Spence, C., Zampini, M. and Gallace, A. (2016). When sandpaper is "kiki" and satin is "bouba": an exploration of the associations between words, emotional states, and the tactile attributes of everyday materials, Multisens. Res. 29, 133-155.

Evans, D. (2001). Emotion: the Science of Sentiment. Oxford University Press, Oxford, UK.

Evans, K. K. and Treisman, A. (2010). Natural cross-modal mappings between visual and auditory features, J. Vis. 10, 6. DOI:10.1167/10.1.6.

Fanger, P. O., Breum, N. O. and Jerking, E. (1977). Can colour and noise influence man's thermal comfort?, Ergonomics 20, 11-18.

Faulkner, W. (1972). Architecture and Color. Wiley-Interscience, New York, NY, USA.

Fenko, A., Schifferstein, H. N. J. and Hekkert, P. (2010). Looking hot or feeling hot: what determines the product experience of warmth?, Mat. Des. 31, 1325-1331.

Fleming, A. (2013). Hot or not? How serving temperature affects the way food tastes. The Guardian (Word of Mouth Blog), September 17th. https://www.theguardian.com/ lifeandstyle/wordofmouth/2013/sep/17/serving-temperature-affects-taste-food.

French, J., Hannon, P. and Brainard, G. C. (1990). Effects of bright light illuminance of body temperature in human performance, Annu. Rev. Chronopharmacol. 7, 37-40.

Gage, J. (1999). Colour and Meaning: Art, Science, and Symbolism. Thames and Hudson, London, UK.

Gallace, A. and Spence, C. (2006). Multisensory synesthetic interactions in the speeded classification of visual size, Percept. Psychophys. 68, 1191-1203. 
Gallace, A. and Spence, C. (2014). In Touch With the Future: The Sense of Touch From Cognitive Neuroscience to Virtual Reality. Oxford University Press, Oxford, UK.

Gallace, A., Ngo, M. K., Sulaitis, J. and Spence, C. (2012). Multisensory presence in virtual reality: possibilities and limitations, in: Multiple Sensorial Media Advances and Applications: New Developments in MulSeMedia, G. Ghinea, F. Andres and S. Gulliver (Eds), pp. 1-38. IGI Global, Hershey, PA, USA.

Getz, L. M. and Kubovy, M. (2018). Questioning the automaticity of audiovisual correspondences, Cognition 175, 101-108.

Gilbert, A. N., Martin, R. and Kemp, S. E. (1996). Cross-modal correspondence between vision and olfaction: the color of smells, Am. J. Psychol. 109, 335-351.

Gilbert, A. N., Fridlund, A. J. and Lucchina, L. A. (2016). The color of emotion: a metric for implicit color associations, Food Qual. Pref. 52, 203-210.

Green, B. G. (1992a). The sensory effects of I-menthol on human skin, Somatosens. Mot. Res. 9, 235-244.

Green, B. G. (1992b). The effects of temperature and concentration on the perceived intensity and quality of carbonation, J. Chem. Senses 17, 435-450.

Greene, T. C. and Bell, P. A. (1980). Additional considerations concerning the effects of 'warm' and 'cool' wall colours on energy conservation, Ergonomics 23, 949-954.

Guéguen, N. and Jacob, C. (2012). Coffee cup color and evaluation of a beverage's "warmth quality", Color Res. Appl. 39, 79-81. DOI:10.1002/col.21757.

Gulak, M. B. (1991). Architectural guidelines for state psychiatric hospitals, Hosp. Community Psychiatry 42, 705-707.

Hamilton-Fletcher, G., Pisanski, K., Reby, D., Stefanczyk, M., Ward, J. and Sorokowska, A. (2018). The role of visual experience in the emergence of cross-modal correspondences, Cognition 175, 114-121.

Hamilton-Fletcher, G. and Ward, J. (2013). Representing colour through hearing and touch in sensory substitution devices, Multisens. Res. 26, 503-532.

Hardin, C. L. (2000). Red and yellow, green and blue, warm and cool: explaining color appearance, J. Consc. Stud. 7, 113-122.

Harris, C. M. (1967). Absorption of Sound in Air versus Humidity and Temperature. NASA Technical Report CR-647. Columbia University, New York, NY, USA. Retrieved from: https://ntrs.nasa.gov/archive/nasa/casi.ntrs.nasa.gov/19670007333.pdf.

Hertenstein, M. J., Keltner, D., App, B., Bulleit, B. A. and Jaskolka, A. R. (2006). Touch communicates distinct emotions, Emotion 6, 528-533.

Hertenstein, M. J., Holmes, R., McCullough, M. and Keltner, D. (2009). The communication of emotion via touch, Emotion 9, 566-573.

Ho, H.-N., Iwai, D., Yoshikawa, Y., Watanabe, J. and Nishida, S. (2014a). Combining colour and temperature: a blue object is more likely to be judged as warm than a red object, Sci. Rep. 4, 5527. DOI:10.1038/srep05527.

Ho, H.-N., Van Doorn, G. H., Kawabe, T., Watanabe, J. and Spence, C. (2014b). Colourtemperature correspondences: when reactions to thermal stimuli are influenced by colour, PLoS One 9, e91854. DOI:10.1371/journal.pone.0091854.

Iosifyan, M. and Korolkova, O. (2019). Emotions associated with different textures during touch, Consc. Cogn. 71, 79-85.

Iosifyan, M., Korolkova, O. and Vlasov, I. (2017). Emotional and semantic associations between cinematographic aesthetics and haptic perception, Multisens. Res. 30, 783-798. 
Itten, J. (2002). The Art of Color: the Subjective Experience and Objective Rationale of Color. John Wiley, New York, NY, USA.

Johnson, K. O., Darian-Smith, I., LaMotte, C., Johnson, B. and Oldfield, S. (1979). Coding of incremental changes in skin temperature by a population of warm fibers in the monkey: correlation with intensity discrimination in man, J. Neurophysiol. 42, 1332-1353.

Jonauskaite, D., Althaus, B., Dael, N., Dan-Glauser, E. and Mohr, C. (2019). What color do you feel? Color choices are driven by mood, Color Res. Appl. 44, 272-284.

Jraissati, Y. and Wright, O. (2018). Cross-modal correspondences between colour and touch: does hue matter?, in: Progress in Colour Studies: Cognition, Language and Beyond, L. W. MacDonald, C. P. Biggam and G. V. Paramei (Eds), pp. 147-161. John Benjamins, Amsterdam, The Netherlands.

Kanaya, S., Matsushima, Y. and Yokosawa, K. (2012). Does seeing ice really feel cold? Visualthermal interaction under an illusory body-ownership, PLoS One 7, e47293. DOI:10.1371/ journal.pone.0047293.

Kanaya, S., Kariya, K. and Fujisaki, W. (2016). Cross-modal correspondence among vision, audition, and touch in natural objects: an investigation of the perceptual properties of wood, Perception 45, 1099-1114.

Kandinsky, W. (1977). Concerning the Spiritual in Art, Especially in Painting (transl. M. T. H. Sadler). Dover Publications, New York, NY, USA.

Kearney, G. E. (1966). Hue preferences as a function of ambient temperatures, Aust. J. Psychol. 18, 271-275.

Khalsa, S. B. S., Jewett, M. E., Cajochen, C. and Czeisler, C. A. (2003). A phase response curve to single bright light pulses in human subjects, J. Physiol. 549, 945-952.

Kim, M.-J., Lee, J.-H. and Han, K.-H. (2006). The effect of color on apparent warmth and judgment distortion, Korean J. Sci. Emot. Sens. 9, 341-351.

Kim, Y.-J. (2013). Can eyes smell? Cross-modal correspondences between color hue-tone and fragrance family, Color Res. Appl. 38, 139-156.

Kimura, T. (1950). Apparent warmth and heaviness of colours, Jpn. J. Psychol. 20, 33-36.

Kwon, J. Y. and Parsons, K. (2008). Heat and cold stress indices for people exposed to our changing climate, in: EKC2008 Proceedings of the EU-Korea Conference on Science and Technology, S.-D. Yoo (Ed.), Springer Proceedings in Physics, Vol. 124, pp. 467-476. Springer-Verlag, Heidelberg, Germany.

Labbe, D., Gilbert, F. and Martin, N. (2008). Impact of olfaction on taste, trigeminal, and texture perceptions, Chemosens. Percept. 1, 217-226.

Landgrebe, M., Nyuki, K., Frank, E., Steffens, T., Hauser, S., Eichhammer, P., Hajak, G. and Langguth, B. (2008). Effects of colour exposure on auditory and somatosensory perception - hints for cross-modal plasticity, Neuroendocrinol. Lett. 29, 518-521.

Levitan, C. A., Ren, J., Woods, A. T., Boesveldt, S., Chan, J. S., McKenzie, K. J., Dodson, M., Levin, J. A., Leong, C. X. R. and van den Bosch, J. J. F. (2014). Cross-cultural color-odor associations, PLoS One 9, e101651. DOI:10.1371/journal.pone.0101651.

Lewinski, R. J. (1938). An investigation of individual responses to chromatic illumination, J. Psychol. 6, 155-160.

Lewkowicz, D. J. and Turkewitz, G. (1980). Cross-modal equivalence in early infancy: auditory-visual intensity matching, Dev. Psychol. 16, 597-607. 
Li, W., Nee, A. Y. C. and Ong, S. K. (2017). A state-of-the-art review of augmented reality in engineering analysis and simulation, Multimodal Technol. Interact. 1, 17. DOI:10.3390/ mti1030017.

Lichtenfeld, S., Maier, M. A., Elliott, A. J. and Pekrun, R. (2009). The semantic red effect: processing the word red undermines intellectual performance, J. Exp. Soc. Psychol. 45, 1273-1276.

Lin, M. C. and Otaduy, M. (Eds) (2008). Haptic Rendering: Foundations, Algorithms, and Applications. AK Peters, Wellesley, MA, USA.

Lockley, S. W., Evans, E. E., Scheer, F. A. J. L., Brainard, G. C., Czeisler, C. A. and Aeschbach, D. (2006). Short-wavelength sensitivity for the direct effects of light on alertness, vigilance, and the waking electroencephalogram in humans, Sleep 29, 161-168.

Ludwig, V. U. and Simner, J. (2013). What colour does that feel? Tactile-visual mapping and the development of cross-modality, Cortex 49, 1089-1099.

MacIsaac, D., Kanner, G. and Anderson, G. (1999). Basic physics of the incandescent lamp (lightbulb), Phys. Teach. 37, 520-525.

MacRae, C. N., Raj, R. S., Best, S. B., Christian, B. M. and Miles, L. K. (2013). Imagined sensory experiences can shape person perception: it's a matter of visual perspective, J. Exp. Soc. Psychol. 49, 595-598.

Marinetti, F. T. (1921). Il Tattilismo. Milan. [Translated in English in La futurista: Benedetta Cappa Marinetti, L. Panzera and C. Blum (Eds), pp. 54-56. Goldie Paley Gallery - Moore College of Art and Design, Philadelphia, PA, USA (1998).]

Marinetti, F. T. (1932/2014). The Futurist Cookbook (transl. S. Brill, 1989). Penguin Books, London, UK.

Marks, L. E. (1974). On associations of light and sound: the mediation of brightness, pitch, and loudness, Am. J. Psychol. 87, 173-188.

Marks, L. E. (1984). Synaesthesia and the arts, in: Cognitive Processes in the Perception of Art, W. R. Crozier and A. J. Chapman (Eds), Advances in Psychology, Vol. 19, pp. 427-447. Elsevier, Amsterdam, The Netherlands.

Marks, L. E. (1987). On cross-modal similarity: auditory-visual interactions in speeded discrimination, J. Exp. Psychol. Hum. Percept. Perform. 13, 384-394.

Marks, L. E. (1989). On cross-modal similarity: the perceptual structure of pitch, loudness, and brightness, J. Exp. Psychol. Hum. Percept. Perform. 15, 586-602.

Marks, L. E. (2004). Cross-modal interactions in speeded classification, in: Handbook of Multisensory Processes, G. A. Calvert, C. Spence and B. E. Stein (Eds), pp. 85-105. MIT Press, Cambridge, MA, USA.

Marks, L. E., Szczesiul, R. and Ohlott, P. (1986). On the cross-modal perception of intensity, J. Exp. Psychol. Hum. Percept. Perform. 12, 517-534.

Martini, M., Perez-Marcos, D. and Sanchez-Vives, M. V. (2013). What color is my arm? Changes in skin color of an embodied virtual arm modulates pain threshold, Front. Hum. Neurosci. 7, 438. DOI:10.3389/fnhum.2013.00438.

Martino, G. and Marks, L. E. (1999). Perceptual and linguistic interactions in speeded classification: tests of the semantic coding hypothesis, Perception 28, 903-923.

Martino, G. and Marks, L. E. (2000). Cross-modal interaction between vision and touch: the role of synesthetic correspondence, Perception 29, 745-754.

Martino, G. and Marks, L. E. (2001). Synesthesia: strong and weak, Curr. Dir. Psychol. Sci. 10, 61-65. 
Matsubara, N., Gassho, A. and Kurazumi, Y. (2004). Facilitatory effects of environmental sounds on hue-heat phenomena, in: 18th International Congress on Acoustics, 2, Kyoto, Japan, pp. 1775-1778.

McBurney, D. H., Collings, V. B. and Glanz, L. M. (1973). Temperature dependence of human taste responses, Physiol. Behav. 11, 89-94.

McFarland, R. A. (1985). Relationship of skin temperature changes to the emotions accompanying music, Biofeedback Self Regul. 10, 255-267.

McGlone, F. and Spence, C. (2010). Editorial: the cutaneous senses: touch, temperature, pain/itch, and pleasure, Neurosci. Biobehav. Rev. 34, 145-147.

Michael, G. A. and Rolhion, P. (2008). Cool colors: color-induced nasal thermal sensations, Neurosci. Lett. 436, 141-144.

Michael, G. A., Galich, H., Relland, S. and Prud'hon, S. (2010). Hot colors: the nature and specificity of color-induced nasal thermal sensations, Behav. Brain Res. 207, 418-428.

Mogensen, M. F. and English, H. B. (1926). The apparent warmth of colors, Am. J. Psychol. 37, 427-428.

Morgan, G. A., Goodson, F. E. and Jones, T. (1975). Age differences in the associations between felt temperatures and color choices, Am. J. Psychol. 88, 125-130.

Morita, T., Teramoto, Y. and Tokura, H. (1995). Inhibitory effect of light of different wabelengths on the fall of core temperature during the nighttime, Jpn. J. Physiol. 45, 667-671.

Morita, T. and Tokura, H. (1995). The influence of different wavelengths of light on human biological rhythms, Appl. Hum. Sci. 17, 91-96.

Moseley, G. L. and Arntz, A. (2007). The context of a noxious stimulus affects the pain it evokes, Pain 133, 64-71.

Motoki, K., Saito, T., Nouchi, R., Kawashima, R. and Sugiura, M. (2019). Light colors and comfortable warmth: crossmodal correspondences between thermal sensations and color lightness influence consumer behavior, Food Qual. Pref. 72, 45-55.

Nafe, J. P. (1934). The pressure, pain, and temperature senses, in: A Handbook of General Experimental Psychology, C. Murchison (Ed.), International University Series in Psychology, pp. 1037-1087. Clark University Press, Worcester, MA, USA.

Nagata, H., Dalton, P., Doolittle, N. and Breslin, P. A. S. (2005). Psychophysical isolation of the modality responsible for detecting multimodal stimuli: a chemosensory example, J. Exp. Psychol. Hum. Percept. Perform. 31, 101-109.

Newhall, S. M. (1941). Warmth and coolness of colours, Psychol. Rec. 4, 198-212.

Occelli, V., Spence, C. and Zampini, M. (2009). Compatibility effects between sound frequencies and tactile elevation, NeuroReport 20, 793-797.

Olson, D., Caporaso, F. and Mandigo, R. (1980). Effects of serving temperature on sensory evaluation of beef steaks from different muscles and carcass maturities, J Food Sci. 45, 627$628,631$.

O'Mahony, M. (1983). Gustatory responses to nongustatory stimuli, Perception 12, 627-633.

Osgood, C. E., Suci, G. J. and Tannenbaum, P. H. (1957). The Measurement of Meaning. University of Illinois Press. Urbana, IL, USA.

Palmer, S. E., Schloss, K. B., Xu, Z. and Prado-León, L. R. (2013). Music-color associations are mediated by emotion, Proc. Natl Acad. Sci. USA 110, 8836-8841.

Parise, C. V. (2016). Crossmodal correspondences: standing issues and experimental guidelines, Multisens. Res. 29, 7-28. 
Parise, C. V. and Spence, C. (2012). Audiovisual crossmodal correspondences and sound symbolism: a study using the implicit association test, Exp. Brain Res. 220, 319-333.

Parise, C. V., Knorre, K. and Ernst, M. O. (2014). Natural auditory scene statistics shapes human spatial hearing, Proc. Natl Acad. Sci. USA 111, 6104-6108.

Pellerin, N. and Candas, V. (2003). Combined effects of temperature and noise on human discomfort, Physiol. Behav. 78, 99-106.

Petit, C. and Sieffermann, J. M. (2007). Testing consumer preferences for iced-coffee: does the drinking environment have any influence?, Food Qual. Pref. 18, 161-172.

Picard, D., Dacremont, C., Valentin, D. and Giboreau, A. (2003). Perceptual dimensions of tactile textures, Acta Psychol. 114, 165-184.

Pöllmann, L. (1994). Circadian and circannual variations in the evaluation of thermal comfort in a constant climate, Indoor Built Environ. 3, 145-148.

Ranasinghe, N., Jain, P., Karwita, S., Tolley, D. and Do, E. Y.-L. (2017). Ambiotherm: enhancing sense of presence in virtual reality by simulating real-world environmental conditions, in: Proceedings of the 2017 CHI Conference on Human Factors in Computing Systems (CHI '17), pp. 1731-1742. ACM, New York, NY, USA. DOI:10.1145/3025453.3025723.

Reppert, S. M. and Weaver, D. R. (2002). Coordination of circadian timing in mammals, Nature 418, 935-941.

Ross, R. T. (1938). Studies in the psychology of the theatre, Psychol. Rec. 2, 127-190.

Saluja, S. and Stevenson, R. J. (2018). Cross-modal associations between real tastes and colors, Chem. Sens. 43, 475-480.

Saysani, A. (2019). How the blind hear colour, Perception 48, 237-241.

Schietecat, A. C., Lakens, D., IJsselsteijn, W. A. and de Kort, Y. A. W. (2018a). Predicting context-dependent cross-modal associations with dimension-specific polarity attributions Part 1 - brightness and aggression, Collabra Psychol. 4, 14. DOI:10.1525/collabra.110.

Schietecat, A. C., Lakens, D., IJsselsteijn, W. A. and de Kort, Y. A. W. (2018b). Predicting context-dependent cross-modal associations with dimension-specific polarity attributions. Part 2: red and valence, Collabra Psychol. 4, 21. DOI:10.1525/collabra.126.

Schifferstein, H. N. J. and Tanudjaja, I. (2004). Visualizing fragrances through colours: the mediating role of emotions, Perception 33, 1249-1266.

Sester, C., Deroy, O., Sutan, A., Galia, F., Desmarchelier, J.-F., Valentin, D. and Dacremont, C. (2013). "Having a drink in a bar": an immersive approach to explore the effects of context on beverage choice, Food Qual. Pref. 28, 23-31.

Shen, Z., Tone, A. and Asayama, M. (1999). The effects of viewing different colors on EEG and skin temperature in humans, J. Int. Soc. Life Inform. Sci. 17, 105-117.

Shermer, D. Z. and Levitan, C. A. (2014). Red hot: the crossmodal effect of color intensity on perceived piquancy, Multisens. Res. 27, 207-223.

Slobodenyuk, N., Jraissati, Y., Kanso, A., Ghanem, L. and Elhajj, I. (2015). Cross-modal associations between color and haptics, Atten. Percept. Psychophys. 77, 1379-1395.

Slocombe, B. G., Carmichael, D. A. and Simner, J. (2016). Cross-modal tactile-taste interactions in food evaluations, Neuropsychologia 88, 58-64.

Smith, L. B. and Sera, M. D. (1992). A developmental analysis of the polar structure of dimensions, Cogn. Psychol. 24, 99-142.

Souman, J. L., Tinga, A. M., te Pas, S. F., van Ee, R. and Vlaskamp, B. N. S. (2017). Acute alerting effects of light: a systematic literature review, Behav. Brain Res. 337, 228-239. 
Sourav, S., Kekunnaya, R., Shareef, I., Banerjee, S., Bottari, D. and Röder, B. (2019). A protracted sensitive period regulates the development of cross-modal sound-shape associations in humans, Psychol. Sci. 30, 1473-1482.

Spence, C. (2011). Crossmodal correspondences: a tutorial review, Atten. Percept. Psychophys. 73, 971-995.

Spence, C. (2018a). Crossmodal correspondences: a synopsis, in: Senses and Sensation: Critical and Primary Sources, Vol. 3, D. Howes (Ed.), pp. 91-125. Bloomsbury Academic, London, UK.

Spence, C. (2018b). Crossmodal contributions to the perception of piquancy/spiciness, J. Sens. Stud. 34, e12476. DOI:10.1111/joss.12476.

Spence, C. (2019a). On the relative nature of (pitch-based) crossmodal correspondences, Multisens. Res. 32, 235-265.

Spence, C. (2019b). On the relationship(s) between colour and taste, Exp. Psychol. 66, 99-111.

Spence, C. (2020). Assessing the role of emotional mediation in explaining crossmodal correspondences involving musical stimuli, Multisens. Res. 33, 1-29.

Spence, C. and Deroy, O. (2013). How automatic are crossmodal correspondences?, Consc. Cogn. 22, 245-260.

Spence, C., Wan, X., Woods, A., Velasco, C., Deng, J., Youssef, J. and Deroy, O. (2015). On tasty colours and colourful tastes? Assessing, explaining, and utilizing crossmodal correspondences between colours and basic tastes, Flavour 4, 23. DOI:10.1186/s13411-0150033-1.

Stevens, J. C. and Choo, K. K. (1998). Temperature sensitivity of the body surface over the life span, Somatosens. Mot. Res. 15, 13-28.

Stevens, J. C. and Hooper, J. E. (1982). How skin and object temperature influence touch sensation, Percept. Psychophys. 32, 282-285.

Stevens, J. C. and Marks, L. E. (1965). Cross-modality matching of brightness and loudness, Proc. Natl Acad. Sci. USA 54, 407-411.

Stevens, S. S. (1957). On the psychophysical law, Psychol. Rev. 64, 153-181.

Stevens, S. S. (1971). Issues in psychophysical measurement, Psychol. Rev. 78, 426-450.

Stevenson, R. J., Rich, A. and Russell, A. (2012). The nature and origin of cross-modal associations to odours, Perception 41, 606-619.

Stewart, N. (2009). The cost of anchoring on credit-card minimum repayments, Psychol. Sci. 20, 39-41.

Suzuki, M., Kimura, R., Kido, Y., Inoue, T., Moritani, T. and Nagai, N. (2017). Color of hot soup modulates postprandial satiety, thermal sensation, and body temperature in young women, Appetite 114, 209-216.

Taft, C. (1997). Colour meaning and context: comparisons of semantic ratings of colours on samples and objects, Color Res. Appl. 22, 40-50.

Takakura, J., Nishimura, T. and Watanuki, S. (2013). Visual information without thermal energy may induce thermoregulatory-like cardiovascular responses, J. Physiol. Anthropol. 32, 26. DOI:10.1186/1880-6805-32-26.

Takakura, J., Nishimura, T., Choi, D., Egashira, Y. and Watanuki, S. (2015). Nonthermal sensory input and altered human thermoregulation: effects of visual information depicting hot or cold environments, Int. J. Biometeorol. 59, 1453-1460.

Talavera, K., Ninomiya, Y., Winkel, C., Voets, T. and Nilius, B. (2007). Influence of temperature on taste perception, Cellul., Molec., \& Life Sci. 64, 377-381. 
Tattersall, G. J., Sinclair, B. J., Withers, P. C., Fields, P. A., Seebacher, F., Cooper, C. E. and Maloney, S. K. (2012). Coping with thermal challenges: physiological adaptations to environmental temperatures, Compr. Physiol. 2, 2151-2202.

Telegraph Reporters (2019). Painting your walls olive green makes the room feel warmer, study finds. The Daily Telegraph, May 26th. https://www.telegraph.co.uk/news/2019/05/26/ painting-walls-olive-green-makes-room-feel-warmer-study-finds/.

Tinker, M. (1938). Effect of stimulus-texture upon apparent warmth and affective value of colors, Am. J. Psychol. 51, 532-535.

Tipler, P. A. and Mosca, G. (2008). Physics for Scientists and Engineers, Vol. 1, 6th edn. Worth Publishers, New York, NY, USA.

Tomaselli, K. G. (2001). Blue is hot, red is cold: doing reverse cultural studies in Africa, Cult. Stud. Crit. Methodol. 1, 283-318.

Tu, Y., Yang, Z. and Ma, C. (2016). The taste of plate: how the spiciness of food is affected by the color of the plate used to serve it, J. Sens. Stud. 31, 50-60.

Tversky, A. and Kahneman, D. (1973). Availability: a heuristic for judging frequency and probability, Cognitive Psychology 5, 207-232.

Van der Zwaag, M. D., Westerink, J. H. D. M. and Van den Broek, E. L. (2011). Emotional and psychophysiological responses to tempo, mode, and percussiveness, Music. Sci. 15, 250 269.

Van Rompay, T. J. L. and Groothedde, S. (2019). The taste of touch: enhancing saltiness impressions through surface texture design, Food Qual. Pref. 73, 248-254.

Velasco, C., Jones, R., King, S. and Spence, C. (2013a). "Hot or cold?" On the informative value of auditory cues in the perception of the temperature of a beverage, in: $(((A B A)))$ Audio Branding Academy Yearbook 2012/2013, K. Bronner, R. Hirt and C. Ringe (Eds), pp. 177-187. Nomos, Baden-Baden, Germany.

Velasco, C., Jones, R., King, S. and Spence, C. (2013b). The sound of temperature: what information do pouring sounds convey concerning the temperature of a beverage, J. Sens. Stud. 28, 335-345.

Velasco, C., Woods, A. T., Deroy, O. and Spence, C. (2015). Hedonic mediation of the crossmodal correspondence between taste and shape, Food Qual. Pref. 41, 151-158.

von Allesch, G. J. (1925). Die aesthetische Erscheinumgsweise der farbe [The aesthetic appearance of colour], Psychol. Forsch. 6, 1-91.

Walker, P. and Smith, S. (1984). Stroop interference based on the synaesthetic qualities of auditory pitch, Perception 13, 75-81.

Walker, P. and Smith, S. (1985). Stroop interference based on the multimodal correlates of haptic size and auditory pitch, Perception 14, 729-736.

Walker, P. and Smith, S. (1986). The basis of Stroop interference involving the multimodal correlates of auditory pitch, Perception 15, 491-496.

Walker, P., Francis, B. J. and Walker, L. (2010). The brightness-weight illusion: darker objects look heavier but feel lighter, Exp. Psychol. 57, 462-469.

Walker, P., Scallon, G. and Francis, B. (2017). Cross-sensory correspondences: heaviness is dark and low-pitched, Perception 46, 772-792.

Walsh, V. (2003). A theory of magnitude: common cortical metrices of time, space and quality, Trends Cogn. Sci. 7, 483-488.

Wang, Q. (J.) and Spence, C. (2017). The role of pitch and tempo in sound-temperature crossmodal correspondences, Multisens. Res. 30, 307-320. 
Wang, Q. J. and Spence, C. (2018). A smooth wine? Haptic influences on wine evaluation, Int. J. Gastron. Food Sci. 14, 9-13.

Wang, Q. (J.), Keller, S. and Spence, C. (2017). Sounds spicy: enhancing the evaluation of piquancy by means of a customised crossmodally congruent soundtrack, Food Qual. Pref. 58, 1-9.

Wastiels, L., Schifferstein, H. N. J., Heylighen, A. and Wouters, I. (2012). Red or rough, what makes materials warmer?, Mater. Des. 42, 441-449.

Wei, X.-X. and Stocker, A. A. (2015). A Bayesian observer model constrained by efficient coding can explain 'anti-Bayesian' percepts, Nat. Neurosci. 18, 1509-1517.

Weinstein, S. (1968). Intensive and extensive aspects of tactile sensitivity as a function of body part, sex, and laterality, in: The Skin Senses, D. R. Kenshalo (Ed.), pp. 195-222. Thomas, Springfield, IL, USA.

Williams, L. E. and Bargh, J. A. (2008). Experiencing physical warmth promotes interpersonal warmth, Science 322, 606-607.

Winzen, J., Albers, F. and Marggraf-Micheel, C. (2014). The influence of coloured light in the aircraft cabin on passenger thermal comfort, Light. Res. Technol. 46, 465-475.

Wnuk, E., de Valk, J. M., Huisman, J. L. A. and Majid, A. (2017). Hot and cold smells: odortemperature associations across cultures, Front. Psychol. 8, 1373. DOI:10.3389/fpsyg.2017. 01373.

Woods, A. T., Spence, C., Butcher, N. and Deroy, O. (2013). Fast lemons and sour boulders: testing crossmodal correspondences using an Internet-based testing methodology, i-Perception 4, 365-369.

Wright, B. (1962). The influence of hue, lightness, and saturation on apparent warmth and weight, Am. J. Psychol. 75, 232-241.

Wright, B. and Rainwater, L. (1962). The meaning of colour, J. Gen. Psychol. 67, 89-99.

Wright, O., Jraissati, Y. and Özçelik, D. (2017). Cross-modal associations between color and touch: mapping haptic and tactile terms to the surface of the Munsell color solid, Multisens. Res. 30, 691-715.

Yasukouchi, A., Yasukouchi, Y. and Ishibashi, K. (2000). Effects of color temperature of fluorescent lamps on body temperature regulation in a moderately cold environment, J. Physiol. Anthropol. Appl. Hum. Sci. 19, 125-134.

Yau, N. J. N. and McDaniel, M. R. (1991). The effect of temperature on carbonation perception, Chemical Senses 16, 337-348. 